\title{
Integrating STI/HIV management strategies into existing MCH/FP programs: Lessons from case studies in East and Southern Africa
}

Baker Ndugga Maggwa

Population Council

lan Askew

Population Council

Follow this and additional works at: https://knowledgecommons.popcouncil.org/departments_sbsr-rh

Part of the Health Services Research Commons, International Public Health Commons, and the Maternal and Child Health Commons

How does access to this work benefit you? Let us know!

\section{Recommended Citation}

Maggwa, Baker Ndugga and lan Askew. 1997. "Integrating STI/HIV management strategies into existing $\mathrm{MCH} / F P$ programs: Lessons from case studies in East and Southern Africa," Africa OR/TA Project II. Nairobi: Population Council. 


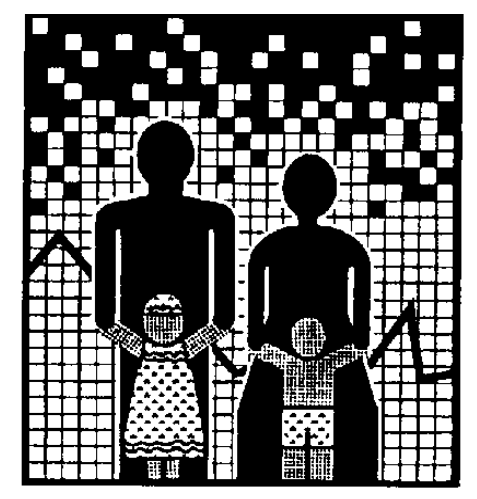

OPERATIONS

RESEARCH

TECHNICAL ASSISTANCE

AFRICA PROJECT II

THE POPULATION COUNCIL

\section{Integrating STI/HIV Management Strategies into Existing MCH/FP Programs:}

Lessons from Case Studies in East and Southern Africa

Baker Ndugga Maggwa

Ian Askew

Africa OR/TA Project II

The Population Council

Nairobi

Kenya

June 1997 


\section{The Population Council}

The Population Council seeks to help improve the well-being and reproductive health of current and future generations around the world and to help achieve a humane, equitable, and sustainable balance between people and resources. The Council analyzes population issues and trends; conducts biomedical research to develop new contraceptives; works with public and private agencies to improve the quality and outreach of family planning and reproductive health services; helps governments to influence demographic behavior; communicates the results of research in the population field to appropriate audiences; and helps build research capacities in developing countries. The Council, a nonprofit, nongovernmental research organization established in 1952, has a multinational Board of Trustees; its New York headquarters supports a global network of regional and country offices.

\section{Africa OR/TA Project II}

The overall objective of the Africa OR/TA Project II is to broaden understanding of how to improve family planning services in Sub-Saharan Africa, and to apply operations research and technical assistance to improve services by:

- $\quad$ increasing access to a full range of family planning services and methods;

- $\quad$ developing service delivery strategies that are client-oriented and acceptable to various population groups;

- $\quad$ improving the operations of programs to make them more efficient and financially sustainable;

- $\quad$ improving the quality of services;

- $\quad$ strengthening the capabilities of family planning program managers to use operations research to diagnose and solve service delivery problems.

This project was supported by the Population Council s Operations Research and Technical Assistance Project II, Project No. 936-3030, and by the Population Council s Cooperative Agreement No. CCP-3050A-00-4013-00, both funded by the United States Agency for International Development (USAID). 


\section{ACKNOWLEDGMENTS}




\section{CONTENTS}

1)

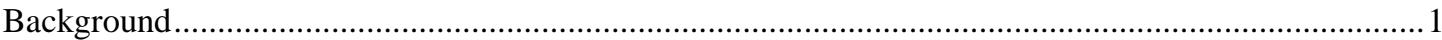

2) Reaching women with STI/HIV services through $\mathrm{MCH} / \mathrm{FP}$ programs .............................................. 4

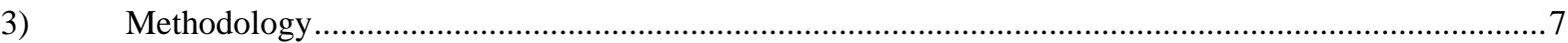

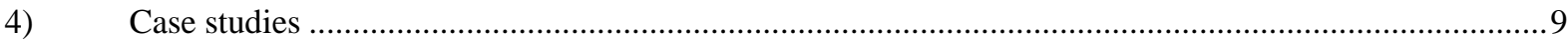

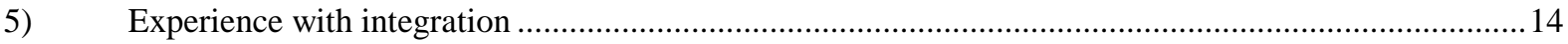

5.1) Management of STIs amongst women

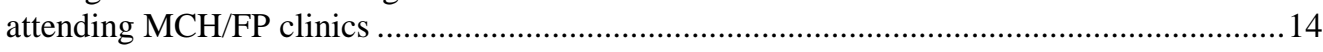

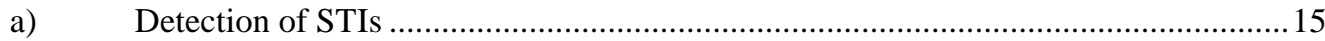

i) Behavioral risk assessment

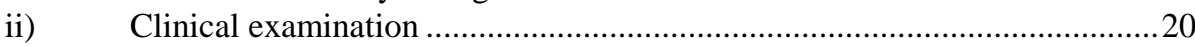

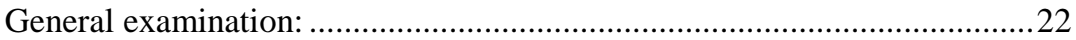

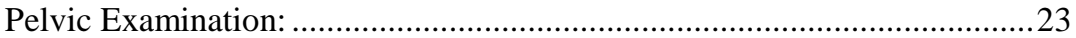

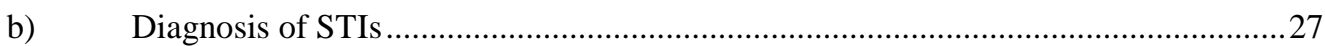

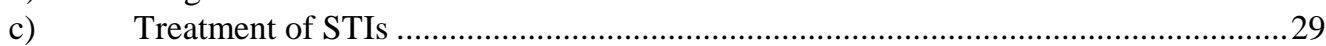

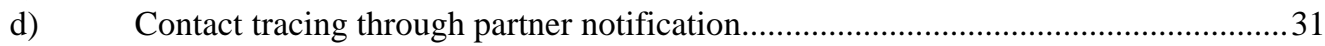

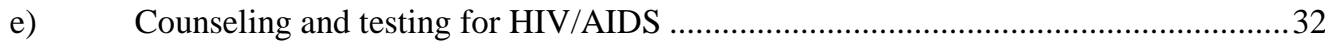

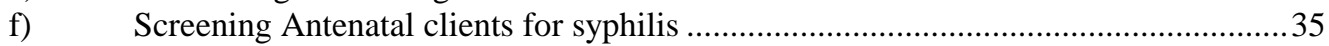

5.2) Improving health-seeking behavior and

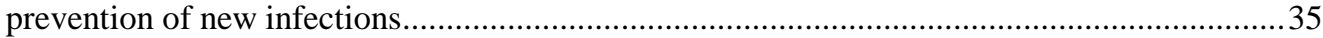

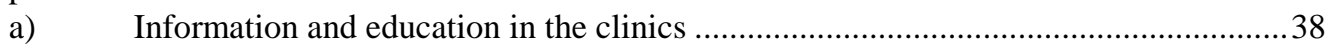

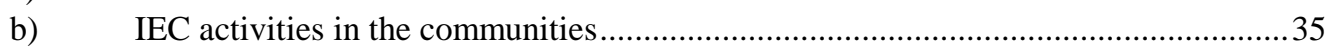

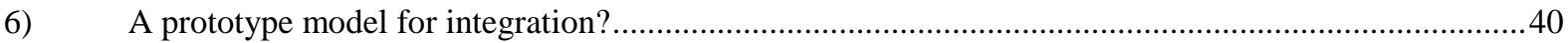

7) Lessons learned, recommendations for programme strengthening and suggestions for further research

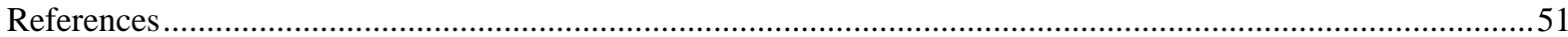




\section{1) Background) Background}

Sub-Saharan Africa is confronting an HIV/AIDS epidemic and consequently virtually all health programs in the region are actively seeking ways of preventing and reducing the spread of this deadly virus. To further compound the problem, the presence of certain sexually transmitted infections ${ }^{1}$ (STIs), particularly genital ulcers but also chlamydia and gonorrhea, is known to increase the risk of the sexual transmission of HIV (see Plummer et al., 1991; Laga, 1992; Hunter et al, 1994; Kapiga et al, 1994). Unfortunately the subSaharan region is also believed to have some of the highest levels in the world of STIs within the general population. Thus the control of STIs is seen not only as an important reproductive health care strategy in itself - their immediate symptoms can be acute and the longer-term obstetric and neonatal complications can be extremely serious for women and infants - but also as a key strategy in reducing the spread of HIV. The strongest evidence to support this has come from the Mwanza Intervention Trial in Tanzania (Grosskurth et al., 1995) which has demonstrated fairly conclusively that improved early detection and treatment of STIs can significantly reduce the incidence of HIV.

A recent review paper by Adler et al (1996) lists the main principles of STI control

as:

i. preventing new infections

ii. treating those with symptoms of infection

iii. improving health seeking behavior amongst those who self-diagnose as being infected

iv. detection and treatment of those with asymptomatic infection

v. improving STI treatment.

1 The term sexually transmitted infection (STI) will be used in this paper, although it is frequently seen as synonymous with the term sexually transmitted disease (STD). Moreover, it is recognized that sexually transmitted infections are only one type of reproductive tract infection (RTI) that can affect women, the others being endogenous overgrowths and those caused iatrogenically through medical procedures. The focus in this paper is on services to prevent and treat STIs only. 
Putting these principles into practice through health care programmes in sub-Saharan Africa remains a huge challenge, however. The purpose of this paper is to describe the results of a few, selected case studies of efforts that have already been made to address this challenge in east and southern Africa. The case studies document the application of these principles in the context of female clients attending MCH/FP clinics.

The use of MCH/FP clinics as an entry point to managing STIs can be criticized for not directly addressing the needs of three higher risk populations who do not normally attend these clinics: commercial sex workers, men, and sexually-active adolescents. A strong case can be made for targeting interventions specifically for these so-called core groups of high-frequency transmitters (e.g. Piot and Rowley, 1992). It is argued that these are more cost-effective strategies for reducing HIV transmission rates overall because these three groups tend to have above average levels of STI incidence and prevalence and more partners. They are also difficult to reach through standard health care programs and so special interventions have had to be developed. This has resulted, however, in a bias in the allocation of resources towards targeted STI control activities such as specialist maleoriented STI clinics, information and services for sex workers and their clients, and interventions targeted specifically for other high-risk groups, such as truck drivers, the military and the youth.

The extensive sexual networking in much of sub-Saharan Africa by males between commercial and non-commercial partners means, however, that they can frequently serve a bridging role for infections between the high and low risk populations, which can push up the likelihood of infection amongst the so-called lower risk groups of women (e.g. Morris et al, 1996). Women attending MCH/FP clinics are considered to be at lower risk, and generally the levels of STI infection amongst this group are lower than for the higher risk groups. Table 1 gives the prevalence of key STIs found among family planning and antenatal clients in east Africa. These and other studies suggest that there is a wide range of STI prevalence levels and that those at the higher end of the range are not dissimilar to the levels found among higher risk populations (Wasserheit and Holmes, 1992), suggesting that there is not necessarily always a clear-cut difference between the low and high risk populations. 
Table1: Prevalence of STIs among women attending MCH/FP clinics and pregnant women in east Africa

\begin{tabular}{|l|c|c|c|c|}
\hline \multicolumn{1}{|c|}{ STI } & $\begin{array}{c}\text { Nairobi } \\
\text { (1991-92) }\end{array}$ & $\begin{array}{c}\text { Nairobi } \\
\text { FP clients } \\
\text { ANC clients }\end{array}$ & $\begin{array}{c}\text { Rakai } \\
\text { (1996) } \\
\text { pregnant } \\
\text { women }\end{array}$ & $\begin{array}{c}\text { Dar es Salaam } \\
\text { (1991-92) } \\
\text { FP clients }\end{array}$ \\
\hline Gonorrhea & 3.2 & $7.3-8.9$ & 2.4 & 4.2 \\
\hline Syphilis & 1.9 & 3.6 & 7.3 & 2.5 \\
\hline Trichomoniasis & 5.2 & - & 22.4 & 14.3 \\
\hline Candida & - & - & - & 11.5 \\
\hline
\end{tabular}

Nairobi / FP clients: Daly et al (1994)

Nairobi / ANC clients: Temmerman et al (1992)

Rakai / pregnant women: Gray and Wawer (1996)

Dar es Salaam: Gertig et al (1997)

For HIV in particular, these levels are already very high among women in east and southern African countries (see Figure 1), although there are indications of some stabilization in the spread of the pandemic. Given the deadly nature of this particular STI, the implications of the spread of this disease amongst the general population of women are very serious.

Figure 1: Prevalence of HIV among antenatal clients at sentinel sites, 1993 - 1995

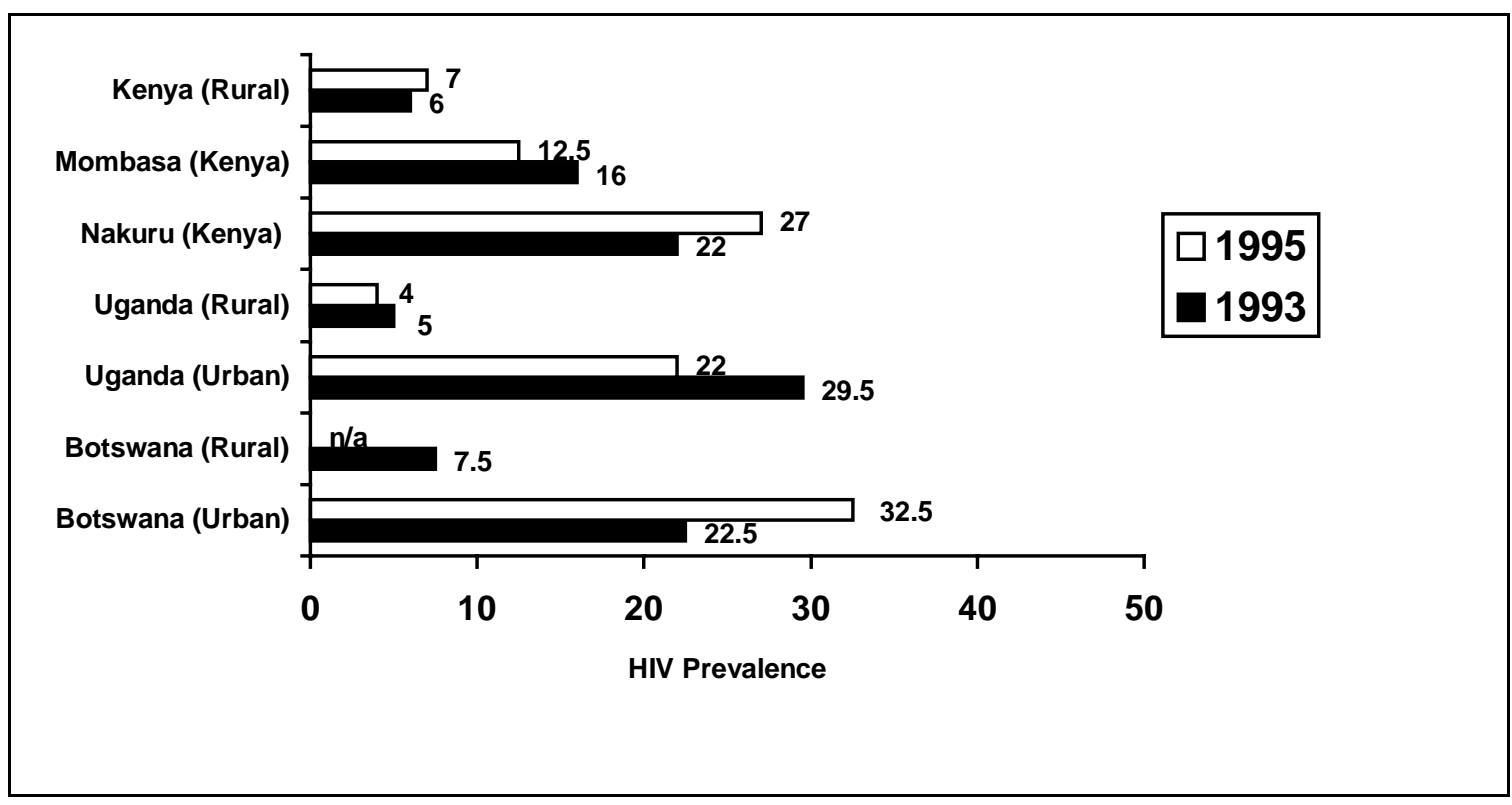


Traditionally, most STI and HIV control programs have not taken women s special circumstances into account during their design and implementation. This has been so despite existing knowledge that women are more vulnerable biologically than men to contracting an STI, that the physical consequences of having an STI are more serious for women than for men, and that women are more likely to be asymptomatic than men (Brunham and Embree, 1992; Hunter et al, 1993; Daly et al, 1994; Gertig et al, 1997). Underlying all of these factors is the socio-cultural and economic inferiority of women which ensures that they are often unable to follow the AIDS prevention strategies currently being promoted, i.e. reduced number of sexual partners; use of condoms; and treatment of STIs. For women in stable unions in particular, it is usually their partner s behavior rather than their own which is the key determinant of their susceptibility to infection (e.g. Caraël et al., 1990), and for the vast majority of women in sub-Saharan Africa this is something over which they have little or no control (see Heise and Elias (1995) and Mason (1994) for a fuller discussion).

\section{2) Reaching women with STI/HIV services through $\mathrm{MCH} / \mathrm{FP}$ programs) Reaching women with STI/HIV services through MCH/FP programs}

Reaching sexually active women within the reproductive age group with information and services that can enable them to more actively control their risk of infection, treat existing infection, and reduce transmission through sexual partners, is therefore a key programmatic issue. Efforts to reach these women through $\mathrm{MCH} / \mathrm{FP}$ programs (both clinic and community-based) is an approach being actively explored for several reasons.

First, as shown in Table 1 above, the prevalence of the common STIs is not insignificant amongst women attending MCH/FP clinics, at least in east and southern Africa. There is clearly a sufficiently high level of infection to justify detecting, treating and preventing further infection amongst this population. Second, MCH/FP clinic clients constitute a numerically much larger population than the high risk groups, and so there are important public health implications for reducing STIs amongst the general population of women. Third, the vast majority of women living in east and southern Africa attend 
$\mathrm{MCH} / \mathrm{FP}$ clinics fairly regularly for antenatal, child welfare and/or family planning services (see Table 2), and so there are quite frequent opportunities for including STI screening, counseling and education during visits for $\mathrm{MCH}$ or family planning services. Fourth, $\mathrm{MCH} / \mathrm{FP}$ services are provided by medically trained staff with many of the same skills needed for managing STIs, and so the additional training needed for them to provide STI management services is minimal. Fifthly, transmission of infections from mother to infant during pregnancy and/or childbirth can be greatly reduced by detecting and treating the infection early in the pregnancy.

\section{Table 2: Proportion of women attending} a clinic for antenatal care

\begin{tabular}{|l|c|}
\hline Country & Percent of women \\
\hline Botswana (1988) & 92 \\
\hline Kenya (1993) & 95 \\
\hline Uganda (1995) & 91 \\
\hline Tanzania (1996) & 89 \\
\hline Zambia (1996) & 92 \\
\hline Zimbabwe (1994) & 93 \\
\hline
\end{tabular}

Source: National DHS surveys

Clearly a strong rationale exists, in principle, for developing and testing interventions that integrate STI/HIV control services with existing MCH/FP services. Balanced against these reasons, however, are a number of equally serious concerns about the feasibility, acceptability, effectiveness and cost-effectiveness of integrating the two currently separate services. Some of the key arguments for and against integrating these two services are presented in summary form in the accompanying box. The purpose of this paper is to provide empirical evidence to assist policymakers, program managers and donors in deciding whether or not to pursue a strategy of service integration. (??) 


\begin{tabular}{|c|c|}
\hline Advantages & Disadvantages \\
\hline $\begin{array}{l}\text { 1. } \mathrm{MCH} / \mathrm{FP} \text { services are already well established and } \\
\text { accepted by clients, providing a credible source of } \\
\text { information and services. }\end{array}$ & $\begin{array}{l}\text { 1. Adding STI/HIV services to } \mathrm{MCH} / \mathrm{FP} \\
\text { programs may overload a relatively weak } \\
\text { infrastructure. }\end{array}$ \\
\hline $\begin{array}{l}\text { 2. If provided within the context of routine } \mathrm{MCH} / \mathrm{FP} \\
\text { services, a woman can receive STI services } \\
\text { anonymously. } \\
\text { 3. Adding STI/HIV services may improve }\end{array}$ & $\begin{array}{l}\text { 2. STIs and HIV/AIDS are stigmatized by } \\
\text { many communities and adding them to } \\
\text { MCH/FP programs might harm the image of } \\
\text { these programs. }\end{array}$ \\
\hline $\begin{array}{l}\text { acceptability and utilization of MCH/FP services } \\
\text { by broadening clinic functions. }\end{array}$ & $\begin{array}{l}\text { 3. There are differences between } \mathrm{MCH} / \mathrm{FP} \text { and } \\
\text { STI/HIV services that warrant different IEC }\end{array}$ \\
\hline 4. $\mathrm{MCH} / \mathrm{FP}$ programs already have experience of & messages and approaches. \\
\hline $\begin{array}{l}\text { providing IEC and distributing condoms, both of } \\
\text { which are essential for preventing STIs and HIV. }\end{array}$ & $\begin{array}{l}\text { 4. } \mathrm{MCH} / \mathrm{FP} \text { services rely heavily on donor } \\
\text { funds and adding STI/HIV services may }\end{array}$ \\
\hline $\begin{array}{l}\text { 5. Both } \mathrm{MCH} / \mathrm{FP} \text { and } \mathrm{STI} / \mathrm{HIV} \text { services are targeted } \\
\text { for sexually active women. }\end{array}$ & $\begin{array}{l}\text { further compromise the viability and } \\
\text { sustainability of these programs. }\end{array}$ \\
\hline $\begin{array}{l}\text { 6. Staff providing } \mathrm{MCH} / \mathrm{FP} \text { services have been } \\
\text { trained in most of the basic procedures required to } \\
\text { provide STI/HIV health services. }\end{array}$ & $\begin{array}{l}\text { 5. The additional requirement for providing } \\
\text { STI/HIV services will increase the overall } \\
\text { cost of implementing an MCH/FP program. }\end{array}$ \\
\hline $\begin{array}{l}\text { 7. The cost to the program and the client of adding } \\
\text { STI/HIV services to an existing MCH/FP program } \\
\text { are expected to be lower than operating a parallel } \\
\text { program for the same clientele. }\end{array}$ & $\begin{array}{l}\text { 6. The possibility of cross-infection with STIs, } \\
\text { and especially HIV, may create fears among } \\
\text { staff and subsequent failure to carry out } \\
\text { proper clinical procedures when providing } \\
\text { MCH/FP services. }\end{array}$ \\
\hline $\begin{array}{l}\text { 8. } \mathrm{MCH} / \mathrm{FP} \text { programs have established contraceptive } \\
\text { and immunization commodity distribution systems } \\
\text { that could be adapted for managing STI/HIV } \\
\text { commodities. } \\
\text { 9. Management information systems (MIS) already } \\
\text { exist for MCH/FP services and would require }\end{array}$ & $\begin{array}{l}\text { 7. An emphasis on barrier methods for } \\
\text { STI/HIV prevention may lead to a reduction } \\
\text { in use of more effective non-barrier } \\
\text { contraceptive methods among couples, with } \\
\text { subsequent increase in unwanted/unplanned } \\
\text { pregnancies. }\end{array}$ \\
\hline minimal adjustments to include STI/HIV services. & $\begin{array}{l}\text { 8. The prevalence of STIs among women } \\
\text { attending MCH/FP clinics is relatively low } \\
\text { and reducing prevalence within this group } \\
\text { may not have a major impact on the overall } \\
\text { prevalence. }\end{array}$ \\
\hline
\end{tabular}

\section{Advantages and disadvantages of Interating STI/HIV and MCH/FP Service}




\section{3) Methodology3) Methodology}

Despite the growing literature on why an integrated approach should or should not be implemented, very little is known about how such services could be integrated and what happens when such a strategy is implemented. The ideal way to address this question would be to test prospectively a number of alternative integration strategies with rigorous research designs that would provide information on all aspects of their implementation, and on their impact on the prevalence of STI and HIV prevalence in the general population (Langer, 1996). As the Mwanza Intervention Trial has shown, however, this can be an extremely resource-intensive and long-term undertaking. An alternative approach, which forms the basis of this report, is to undertake case studies of existing and comparable efforts to integrate services (Mayhew, 1996) and to synthesize the findings. Although the concept of integration is fairly recent, a number of examples do exist of NGO and governmental programs seeking to integrate some aspects of STI control services into their MCH/FP programs. Case studies of four such programs form the basis of this report: the Mkomani Clinic Society's MCH/FP program in Mombasa, Kenya; the Busoga Diocese Family Life Education Project in Uganda; the Nakuru Municipal Council program; and the 'BOTSPA' Project of the Botswana national MCH/FP program. These case studies were selected in collaboration with other members of the USAID-supported Regional Integration Partnership for East and Southern Africa (Pathfinder International, USAID REDSO/ESA, USAID Africa Bureau, Family Health International s AIDSCAP Project and Population Division, the U.S. Centers for Disease Control, and Harvard University s Data for Decision Making Project), under whose auspices this study has been carried out.

While the case study approach lacks the degree of control over the intervention design and data collection which is possible in a prospective experimental study, it does allow the real-life experiences of program managers, staff and clients to be documented in a way that can describe the process of implementation and give guidance as to the feasibility of an integrated approach. Those approaches which look promising can then be strengthened and their impact on the cost-effectiveness of identifying, treating and preventing STI infections within the general population evaluated. 
The following multi-component methodology was used for conducting the case studies:

Review of available reports and data for each program

In-depth interview with program managers

Inventory of facilities, equipment, supplies and drugs available at all program facilities

Observations of client/service provider interactions where possible

Exit interviews with clients receiving $\mathrm{MCH}, \mathrm{FP}$ and STI services

Interviews with service providers.

These data collection instruments were used for three of the case studies, and were based on those developed for the Situation Analysis approach ${ }^{2}$ to assess the functioning and quality of family planning services; the standard instruments were adapted and expanded to include additional items for assessing STI and HIV/AIDS services. The case study of the Botswana $\mathrm{MCH} / \mathrm{FP}$ program was undertaken somewhat differently, in that the national program was assessed prior to the introduction of the USAID-supported integration intervention through a Situation Analysis study. One year after the intervention a modified form of the case study instruments was developed and used to evaluate the effect of the intervention on the performance of a sample of clinics and staff trained. Data presented in this report are drawn primarily from the evaluation study, although where appropriate data from the Situation Analysis study are used.

For two of the smaller programs (the Mkomani Clinic Society in Mombasa, Kenya, and the Nakuru Municipal Council in Kenya) it was possible to visit all clinics in the program, but for the Botswana national MCH/FP program and the Busoga Diocese program in Uganda it was necessary to draw a representative sample of clinics. The numbers of interviews, observations and inventories through which data were collected are given on Table 3 below. 
Table 3: Sample sizes for data collected during the case studies

\begin{tabular}{|l|c|c|c|c|c|}
\hline \multicolumn{1}{|c|}{ Study Site } & $\begin{array}{c}\text { Clinics } \\
\text { visited }\end{array}$ & $\begin{array}{c}\text { Clinic staff } \\
\text { interviewed }\end{array}$ & $\begin{array}{c}\text { Community } \\
\text { workers } \\
\text { interviewed }\end{array}$ & $\begin{array}{c}\text { MCH/FP } \\
\text { clients } \\
\text { interviewed }\end{array}$ & $\begin{array}{c}\text { Client- } \\
\text { provider } \\
\text { interactions } \\
\text { observed }\end{array}$ \\
\hline Busoga, Uganda & 17 & 21 & 45 & 117 & 65 \\
\hline Nakuru, Kenya & 7 & 23 & 0 & 72 & 72 \\
\hline Mkomani, Kenya & 2 & 12 & 14 & 36 & 0 \\
\hline BOTSPA sites, Botswana & 25 & 38 & 0 & 164 & 164 \\
\hline
\end{tabular}

\section{4) Case studies) Case studies}

This paper reports on case studies of four programs where some form of service integration has been attempted. There is a wide variation in program designs, objectives and locations and the case studies selected represent both urban and rural settings, and include an NGO effort, a church-based initiative, an urban municipal council program, and a national government program. Each program is described briefly below. 


\section{Mkomani Clinic Society, Mombasa, Kenya}

The Mkomani Clinic Society (MCS) is a private charitable organization founded in 1980. The organization started providing basic curative services, including STI services, antenatal care and child welfare services at one clinic. With donor assistance in 1982, the MCS began providing family planning services in the clinic and started a community outreach program on family planning information and services, which now has 30 full-time Community Service Workers (CSWs) who have a broad reproductive health role. In 1986, a second clinic was established, providing the same services. Both clinics have a basic on-site laboratory and refer more complex cases, including HIV testing, to other laboratories. Until 1992, services were provided separately at different departments within the clinics and on different days. With technical assistance from Pathfinder International, MCS began to integrate STI/HIV counseling and screening into the routine MCH/FP service delivery. This intervention consisted of: appointing two extra nurses; in-house training for all nurses in the syndromic approach to STI diagnosis; seminars for all clinic support staff on infection prevention and safe sexual practices; developing protocols and provider guidelines for integrated services; and in-house training for CSWs on STI/HIV transmission and signs / symptoms, safer sex and condom promotion; and strengthening the laboratory facilities to include tests for certain STIs. The integration Model adapted is as shown in the box below.

\section{The Mkomani Clinic Society Integration Model}

1. Carry out a risk assessment for STI/HIV/AIDS among all clients visiting the clinics for family planning, antenatal and child welfare services;

2. Provide information on STI/HIV/AIDS to all clients who receive any services at the clinics or from the CSWs;

3. Inform the public about STIs and HIV/AIDS and the availability of services at the MCS clinics through public meetings and seminars;

4. Protect health personnel and MCH-FP clients from infection during clinic procedures;

5. Test all ANC clients for syphilis;

6. Diagnose and treat common STIs within the MCH-FP unit;

7. Identify and refer all clients with symptoms/signs of HIV infection, or those requesting HIV testing, to institutions with established HIV counseling and testing facilities;

8. Carry out partner notification for sexual contacts and treatment for those traced.

For the full case study report see Twahir et al. (1996). 


\section{Nakuru Municipal Council, Kenya ${ }^{4}$}

There are seven public sector clinical facilities in Nakuru town. The Nakuru Municipal Council (NMC) operates five health centers, all of which provide basic antenatal, child welfare, STI and other curative services; four of these provide family planning services. The Provincial Referral Hospital, operated by the $\mathrm{MOH}$, provides MCH-FP and STI/HIV services and has a laboratory, and there is also an STI treatment clinic. Since 1989, all seven facilities have been collaborating in a project with the Department of Community Health at the University of Nairobi, the University of Manitoba, Canada, and the Nairobi City Council. The project is jointly funded by the Canadian International Development Agency (CIDA) and the Kenya Government, and seeks to strengthen the clinic-based management of STIs and HIV/AIDS and to establish sustainable community-based STI/AIDS control activities, with a special emphasis on women s participation. The intervention consisted of: training providers in syndromic diagnosis and treatment of STIs; equipping facilities with IEC materials, algorithm flow charts and manuals; supplying drugs for treating STI syndromes; strengthening the laboratory facilities; and introducing a community-based IEC program of peer educators for commercial sex workers and counselors visiting schools and worksites to give talks and provide condoms. The model of integration adapted by the Project is shown in the box below.

\section{The Nakuru Municipal Council Integration Model}

1. Carry out STI and HIV/AIDS risk assessment and screening for all clients receiving MCH-FP and other services at the health facilities;

2. Provide information, educate and counsel all clients receiving services from the health facilities about STIs and HIV/AIDS;

3. Provide information, educate and counsel hard to reach groups like commercial sex workers, men at the workplace and youth in schools using clinic staff and trained peer educators;

4. Diagnose and treat STIs using the syndromic approach and the algorithms available;

5. Refer clients requiring HIV testing and specialized STI treatment to the STI clinic;

6. Prevent cross infections within the health facilities;

7. Carry out contact tracing and treatment for partners of STI clients;

8. Screen and treat all antenatal clients for syphilis. 


\section{Family Life Education Project, Busoga Diocese, Uganda ${ }^{5}$}

The Busoga Diocese of the Anglican Church began the Family Life Education Project (FLEP) in 1986 with support from Pathfinder International. The Project increases access to family planning and other reproductive health services through services at the Diocese s clinics, and through voluntary Village Health Workers (VHWs). All 48 clinics provide family planning, STI/HIV/AIDS counseling and other basic curative services daily, 33 provide child welfare services and 15 provide antenatal care and delivery services. The 162 VHWs counsel, motivate and refer clients for antenatal, postnatal, child welfare, STI and HIV/AIDS services. A team of $20 \mathrm{VHW}$ trained as communication agents performs drama and songs to communicate locally relevant IEC messages, and FLEP has trained 30 community-based teachers and other leaders to teach in- and out-of school youth about reproductive health issues. Each village has a health subcommittee, whose members are trained to mobilize and manage community resources for the construction and operation of the clinics. FLEP has also provided basic equipment and supplies for providing family planning services. The intervention to facilitate an integrated approach consisted of: training all clinic staff and VHWs in HIV/AIDS counseling, and in counseling and management of other STIs; development of risk assessment checklist for clinic staff; establishing a referral arrangement with an NGO for HIV testing and with Government laboratories for other STI tests; and equipping the clinics and VHWs with IEC materials and developing messages for the communication agents. The model of integration adapted by the Project is shown below.

\section{The Family Life Education Project s Integration Model}

1. Carry out STI/HIV risk assessment for clients receiving MCH/FP services from the clinics;

2. Screen clients receiving MCH/FP services for STIs and HIV/AIDS using a diagnostic checklist;

3. Identify and refer clients requiring HIV testing;

4. Diagnose and treat clients with STIs using the syndromic approach;

5. Inform and educate all clients receiving services from the clinics and VHWs about STIs and HIV/AIDS;

6. Inform and educate the general public about STIs/HIV/AIDS through public meetings, drama and song;

7. Inform and educate in and out-of-school youth about STIs and HIV/AIDS using trained school teachers, community leaders, church leaders and private nurse midwives.

8. Raise awareness and create support for the integrated reproductive health services among the health sub-committees and other community leaders.

For the full case study report see Mukaire et al. (1997). 


\section{National MCH/FP Program, Botswana ${ }^{6}$}

Family planning, MCH and STI/HIV services were available daily, although separately, at all three levels of the MOH system (i.e. hospitals, clinics, health posts). In 1992, the MOH introduced the syndromic approach to STI management for those clients attending for STI services. The USAID-supported Botswana Population Assistance (BOTSPA) Project sought to improve the quality, availability and integration of $\mathrm{MCH} / \mathrm{FP} / \mathrm{STI}$ services and to expand AIDS prevention measures through an intervention that consisted of the following components: in-service training for all $\mathrm{MCH} / \mathrm{FP}$ personnel, focusing on clinical skills, FP/STI counseling, reporting and use of data; strengthening the existing MIS to record and report indicators of STI and HIV/AIDS services provided, and commodity requirements; training service providers (nurses at hospitals and clinics and the Family Welfare Educators at Health Posts) in the use of IEC materials; review and revision of the family planning policy guidelines and standards and procedures manual to include STI and HIV/AIDS services. The model of integration adapted by the Program is shown below.

\section{The Botswana Population Assistance Project Model}

1. Carry out a risk assessment for STI/HIV/AIDS for all MCH-FP clients;

2. Provide information and education on STIs, family planning and relationships between the two to all clients, including promotion of dual contraception;

3. Provide individual counseling for all $\mathrm{MCH} / \mathrm{FP}$ clients identified to be at risk;

4. Use the syndromic approach to diagnose and manage STIs;

5. Carry out community IEC activities through trained Family Welfare Educators to raise awareness about STIs and HIV/AIDS;

6. Establish STI/HIV/AIDS management teams at Centers of Competence and manage referrals from lower health facilities;

7. Practice infection prevention procedures when managing clients;

8. Carry out contact tracing using self-referral cards issued to the index client;

9. Identify and refer clients for HIV testing;

10. Test or refer all antenatal clients for syphilis;

11. Collect, analyze and use data on services at the clinic level. (1997), and for the national baseline Situation Analysis study see Baakile et al. (1996). 


\section{5) Experience with integration5) Experience with integration}

The principles for a successful STI control program identified by Adler et al and listed above were found to varying degrees in each of the case study programs. Because the focal point of interaction with women for all the programs is their attendance at the MCH/FP clinic, most attention appears to have been paid to developing an approach to integration that focuses on the detection and treatment of $\mathrm{MCH} / \mathrm{FP}$ clients with asymptomatic infection, on the treatment of those presenting for $\mathrm{MCH} / \mathrm{FP}$ services with symptoms, and on improving the quality of STI treatment provided. However, all four programs also addressed, or at least showed the potential to address, the prevention of new infections and improving health seeking behavior amongst those who self-diagnose as being possibly infected. How the programs undertook these activities within the context of their $\mathrm{MCH} / \mathrm{FP}$ services is described below.

\section{1) Management of STIs amongst women attending MCH/FP clinics5.1) Management of STIs amongst women attending MCH/FP clinics}

a) Detection of STIsa) Detection of STIs

It should be stressed that in all four programs it is primarily the family planning clients who are being screened ${ }^{7}$; among MCH clients it is only those who come for antenatal services that receive any form of STI screening, and this is normally restricted to detecting syphilis. The integration approach under consideration here is based on the assumption that some women attending clinics for $\mathrm{MCH} / \mathrm{FP}$ services, depending on local conditions, will have one or more STI. It can be assumed also that of those women who have an infection,

$7 \quad$ A distinction has been made in the literature between screening, which is usually undertaken outside of the health facility environment and within high risk groups, and case finding or case detection which is described as a process of opportunistic screening for an infection...... at the time that an individual presents to a health facility regardless of whether they have symptoms suggestive of an STI (Adler et al, 1996:27). Thus the term case detection is more appropriate for these case studies and is used in this report. 
some will know they have the signs and symptoms of an infection but have not yet sought treatment (or are seeking treatment elsewhere), some will have the signs but do not realize that they are symptoms of an STI, and some will be asymptomatic. The proportions of each category are impossible to know, and so staff working in an integrated program have to work on the basis that all women presenting are at risk of having an STI.

Consequently, all four programs have sought to include a method for detecting potential STI cases among women attending these clinics. In all four, STI case detection is supposed to be undertaken through a combination of:

- behavioral risk assessment through asking the client questions about her and her partner s sexual relationships

- clinical history taking;

- and, where possible, clinical examination.

This case detection method (based on identifying risk behavior and clinical symptoms and signs) has been adopted in these programs because it takes into account the limited access to laboratory testing facilities, and because for most new family planning clients these same procedures are normally considered standard practice for good quality care. Revisiting family planning clients are less likely to be screened because unless the woman has come with a problem and/or is seeking to switch to another contraceptive method, data from numerous Situation Analysis studies (e.g. Miller et al. 1996) show that revisit clients are rarely asked risk assessment questions or have a clinical history or exam taken. Whether they should receive the same level of attention as new family planning clients is an often-debated issue, as there are important resource considerations for women using resupply methods who may visit a clinic three or four times a year.

\section{i) Behavioral risk assessment and clinical history taking) Behavioral risk assessment and clinical history taking}

Case detection through risk assessment / history taking can be used either with or without a clinical examination. Although a clinical exam is clearly preferable, it is possible 
to undertake limited case detection in situations where, for whatever reason, it is not possible to undertake a pelvic examination ${ }^{8}$. Moreover, the questions routinely asked of a new family planning client include some (but not all) of the behavioral and other risk factors needed for STI case detection. Consequently, the service delivery guidelines for these four programs also recommend asking new family planning clients some additional questions, which are not part of a routine consultation for (??family planning), to better assess the client and her partner(s) risk of infection.

Each program has developed its own guidelines for training staff in history taking and risk assessment of family planning clients that enhance their ability to detect cases of STI. These are generally based on the service delivery guidelines developed by the country s national STD/AIDS control program. The vast majority of service providers interviewed, however, were not aware that these guidelines existed and did not have written copies.

The risk factors common to all four programs guidelines that were assessed ${ }^{9}$ during the case studies are listed in Table 4 below. Although the number of clients observed was small, the data show quite clearly that few family planning clients were asked about many of these behavioral risk factors. Moreover, the staff from each program appear to put different emphasis on asking different questions. Interestingly, the one question which staff in all four programs asked was the number of sex partners in the last year, suggesting that they are not necessarily afraid of asking questions about sexual behavior. suggest that the majority of clinics do have specula and gloves available, and so in most cases the equipment and supplies needed to carry out a pelvic exam are present. 
Table 4: Percentage of new Family Planning clients asked about risk factors

\begin{tabular}{|l|c|c|c|c|}
\hline \multicolumn{1}{|c|}{ Risk factors } & $\begin{array}{c}\text { Mkomani } \\
(\mathbf{n = 3 6})\end{array}$ & $\begin{array}{c}\text { Busoga } \\
(\mathbf{n = 1 6})\end{array}$ & $\begin{array}{c}\text { Nakuru } \\
(\mathbf{n = 1 0})\end{array}$ & $\begin{array}{c}\text { Botswana } \\
(\mathbf{n = 3 9})\end{array}$ \\
\hline No. of sex partners in past year & 14 & 100 & 20 & 26 \\
\hline Client s marital status & 11 & 0 & 100 & 51 \\
\hline Partner s other sexual partners & 8 & 0 & 0 & 0 \\
\hline Partner s occupation & 0 & 6 & 0 & 33 \\
\hline Partner s residence & 0 & 19 & 0 & 18 \\
\hline History/presence of STIs in partner & 0 & 31 & 30 & 59 \\
\hline History of STIs in client & 0 & 25 & 30 & 61 \\
\hline Client s concerns about STIs & 14 & 25 & 0 & 0 \\
\hline Condom use by client & & & & \\
\hline
\end{tabular}

Although these risk factors were based largely on the national service delivery guidelines, the national guidelines themselves were developed originally for use in situations where clients present with STI symptoms (e.g. STI clinics). They may not, therefore, be immediately useful in $\mathrm{MCH} / \mathrm{FP}$ settings where clients are normally presenting for other services, the prevalence of STIs is relatively low, and over half of the clients with STIs are probably asymptomatic (Daly et al, 1994; Gertig et al, 1997).

Why the service providers are not routinely asking all of the risk assessment questions expected for an integrated approach is an essential issue. Several possible explanations emerged. One possibility is that during the training clear instructions on exactly which questions to ask, how to ask them, and that they should be asked of all clients, were not given. Related to this, it appears that the training materials used, and those given to the providers may be inadequate. Indeed, apart from the FLEP program which provides a checklist to its clinical staff, written guidelines or a checklist to assist the staff in carrying out the risk assessment were not given out and/or were not generally available. 
A related reason may be the fact that none of the programs had revised their family planning client record forms to cater for the additional information to be collected for behavioral risk assessment and history taking related to STIs/HIV. Consequently, although the providers were expected to routinely record this information during their interactions with family planning clients, the client record forms did not have space for this information. There is an expectation, therefore, that the provider not only has to remember which questions to ask without a physical checklist or guide, but also has to find some way of recording the information on a form for which there is no space to do so ${ }^{10}$.

Service providers in the busier clinics cited large client loads as a major reason why they did not routinely undertake the full risk assessment procedures for all family planning and $\mathrm{MCH}$ clients. While this is an understandable reason, it is unclear how much extra time is involved in undertaking an integrated consultation compared with a family planning only consultation, particularly if there are only a few, if any, extra questions to be asked. Indeed, it can be argued that these questions should be asked of a new family planning client anyway if the provider is to be able to assist the client to choose the most appropriate contraceptive method, and not only in relation to detecting potential STI cases. This is an issue which arises frequently in any consideration of providing more than one service at the same time, and would clearly benefit from more research, perhaps in the context of a client flow analysis within a cost-effectiveness study.

A lack of auditory and/or visual privacy during consultations was frequently cited as one reason why providers were unwilling to discuss sexual behavior and STIs with their clients. Except for Nakuru, where all seven facilities had separate rooms for counseling and examinations, half of the Busoga clinics, 60 percent of the Botswana clinics and one of the two Mkomani clinics lacked auditory and visual privacy. Whether much can be done about this depends on the physical structure of the individual facilities and the substantial resources frequently needed to improve privacy.

10 Following the results of the case studies, the Mkomani and Botswana program managers initiated a review and revision of their family planning client record forms to include STI risk assessment questions so that they can serve as both a checklist and comprehensive record of the client s situation. 
Service providers feel that they know their clients well, and frequently cited this relationship as the reason why they did not feel the need to ask about sexual behavior and other risk factors. As a result of not discussing these issues, they were found to have incorrect assumptions about their clients. For example, most providers felt that their clients are not at risk for STIs/HIV, whereas their clients frequently state that they do feel to be at risk -- between 52 - 70 percent of clients interviewed expressed this feeling. Service providers also feel that their clients would be offended by being asked questions about their sexual behavior, but when clients are asked such questions, they appear fairly willing to answer them.

Initiating discussions about STIs can be problematic if MCH/FP clients are not aware of the common symptoms and signs associated with an infection. Almost all women interviewed indicated that they knew of infections that could be transmitted sexually. Table 5 describes the responses these women gave spontaneously when asked to name the symptoms of such infections.

Table 5: Percentage of MCH/FP clients mentioning Symptoms suggestive of STIs

\begin{tabular}{|l|c|c|c|c|}
\hline \multicolumn{1}{|c|}{ Symptom } & $\begin{array}{c}\text { Mkomani } \\
(\mathbf{n = 3 6})\end{array}$ & $\begin{array}{c}\text { Nakuru } \\
(\mathbf{n = 5 1})\end{array}$ & $\begin{array}{c}\text { Busoga } \\
(\mathbf{n = 1 1 7})\end{array}$ & $\begin{array}{c}\text { Botswana } \\
(\mathbf{n = 1 6 3})\end{array}$ \\
\hline Lower abdominal pain & 33 & 32 & 56 & 17 \\
\hline Genital itching & 17 & 27 & 37 & 29 \\
\hline Genital discharge & 47 & 45 & 38 & 44 \\
\hline Painful urination & 39 & 23 & 36 & 34 \\
\hline Genital ulcer & 25 & 23 & 52 & 66 \\
\hline
\end{tabular}

These data suggest that knowledge overall of symptoms is rather low, and clearly there is a need to strengthen awareness among women attending MCH/FP clinics, and presumably in the general population. There is, however, considerable variation between the 
groups in terms of which symptoms they know. For example, genital ulcers were mentioned by two thirds of women in the Botswana group but only a quarter of those in the Mkomani and Nakuru clinics. Whether this reflects variation in the actual prevalence of the symptoms (and their underlying cause) or differences in perception, definition and terminology for abnormal symptoms in the genital area is not at all clear (see Olukoya and Elias (1996) for a discussion of perceptions of reproductive tract morbidity).

Whatever the case, for programs that rely on the syndromic approach it is important that clients have a good knowledge of suggestive symptoms and that there is a common understanding and definition of symptoms by both clients and staff. This is important so that clients can be encouraged to pro-actively identify possible symptoms and so that providers and clients can discuss symptoms and signs with a common understanding of what is normal and what is abnormal.

These clients were Table 6: Percentage of MCH/FP clients mentioning then asked which symptoms, experience of symptoms in previous 12 months if any, they had experienced in the previous 12 months. The data on Table 6 show that symptoms associated with STIs are quite common among women attending $\mathrm{MCH} / \mathrm{FP}$ clinics, and so it is

\begin{tabular}{|l|c|c|c|}
\hline Symptom & $\begin{array}{c}\text { Mkomani } \\
(\mathbf{n = 3 6})\end{array}$ & $\begin{array}{c}\text { Nakuru } \\
(\mathbf{n = 5 1})\end{array}$ & $\begin{array}{c}\text { Busoga } \\
(\mathbf{n}=\mathbf{1 1 7})\end{array}$ \\
\hline Lower abdominal pain & 23 & 17 & 57 \\
\hline Genital itching & 21 & 33 & 25 \\
\hline Genital discharge & 26 & 31 & 23 \\
\hline Painful urination & 9 & 17 & 16 \\
\hline Genital ulcer & 17 & 6 & 15 \\
\hline
\end{tabular}
essential that providers routinely ask clients about them and look for them during a physical exam. This does not seem to be happening currently; for example, in Busoga, only one half of clients were observed to be asked about current or past experiences of vaginal discharge and lower abdominal pain, and about one third were asked about genital itching and genital ulcers. Inadequate history taking may be resulting, therefore, in missed opportunities to detect women at risk of having an STI and reduces the efficacy of the syndromic approach. 


\section{ii) Clinical examinationii) Clinical examination}

\section{General examination:General examination}

In all three countries the national family planning service delivery guidelines require that clients choosing to use a medical contraceptive method (e.g. pill, injectable, IUD, Norplant implant, sterilization) should have a general physical examination which includes: inspection of the skin and mucus membranes, checking for enlarged organs or lymph nodes, and measuring weight and blood pressure. This information is used to decide the suitability of different methods for the client. This general examination also covers all the items necessary to identify those STIs (including HIV) which manifest themselves with generalized physical symptoms like weight loss, anaemia, skin rashes, hair loss and enlarged lymph nodes. A general physical examination is also important for detecting syphilis whose genital symptoms disappear soon after primary infection but whose generalized signs and symptoms stay for long periods.

The extent to which these examinations were performed was encouraging (see Figure 2). For most new family planning client consultations observed, general and breast examinations were carried out and the weight and blood pressure measured. Whether providers were consciously looking for STI symptoms while doing these exams is not known, however. 


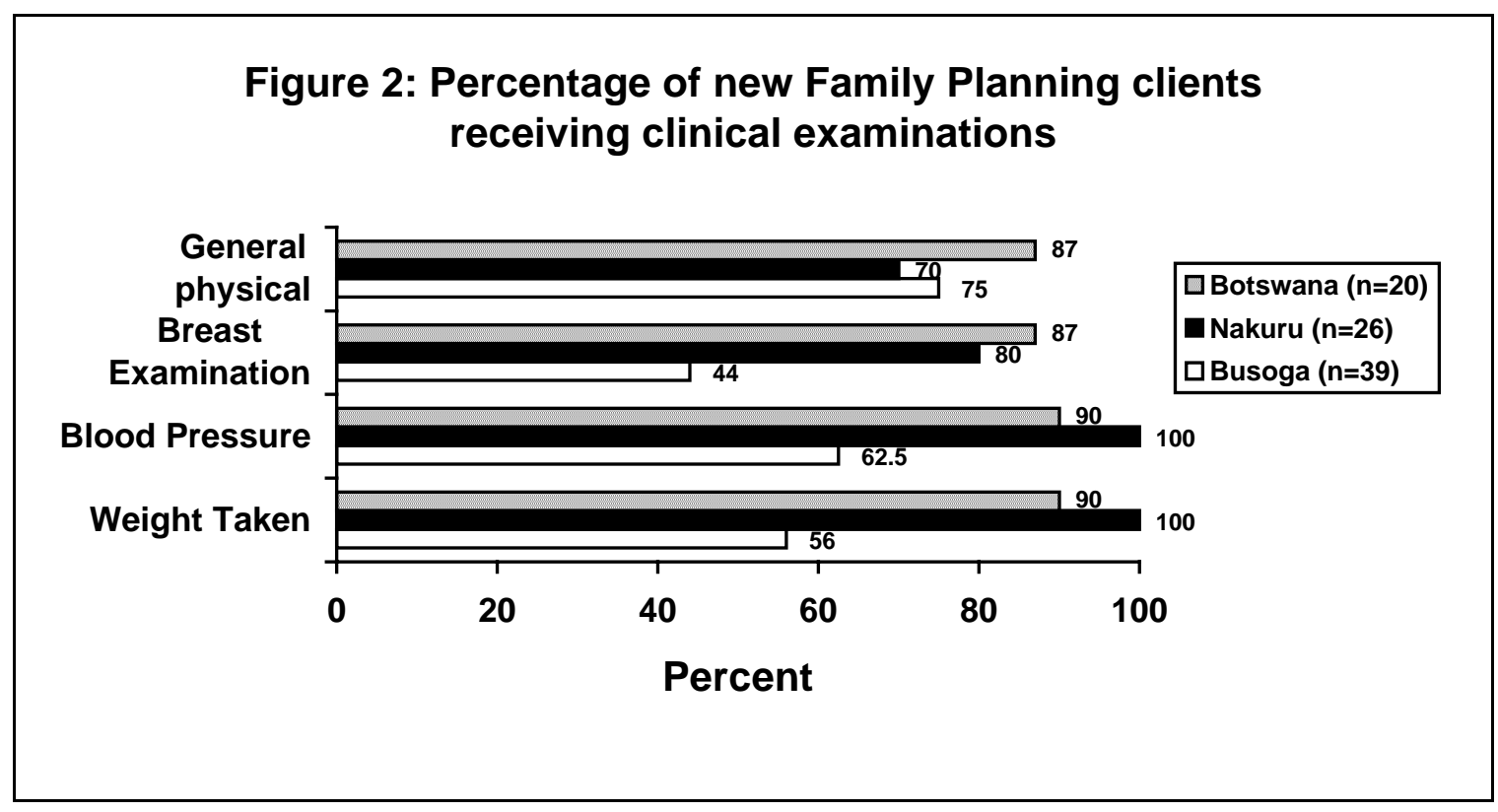

The national guidelines for STI management in all three countries recommend that all clients presenting with STI symptoms should have a general examination to check for other STIs and conditions; infection with more than one STI is not uncommon. However, at the STI clinic in Nakuru, 12 clients presenting with symptoms of STIs were observed, but only two had a general examination. This suggests that when staff are focusing on providing STI services alone, they also do not follow recommended procedures.

\section{Pelvic Examination:}

\section{Pelvic Examination}

Most programs require or strongly recommend that the provider undertake a pelvic examination for all new family planning clients choosing to use a medical contraceptive method. A full pelvic examination includes inspection of the external genitalia, bimanual palpation, and a speculum examination. A pelvic examination, either external or internal, is clearly a useful additional component to an STI case detection method because it can be used to detect, through direct observation, certain signs and symptoms which a woman may have but does not recognize (e.g. Olukoya and Elias, 1996), or which she knows she has but does not want to report verbally. A pelvic exam will also increase the likelihood of the provider finding cases of RTIs which are not necessarily sexually transmitted, such as candidiasis and bacterial vaginosis. 
An external examination, if undertaken thoroughly, would allow the provider to find and/or confirm cases of vaginal discharge and genital ulcers, two of the syndromes commonly used during syndromic diagnosis. If a provider is also able to carry out a bimanual palpation and a speculum examination, this would allow the identification of intravaginal / cervical ulcers and cervical inflammation. It would also allow a distinction to be made between a vaginal and cervical discharge, which is important for determining the possible aetiological agents for the discharge. Cervical discharges are more likely to be due to gonorrhea and/or chlamydia, while vaginal discharges are mostly due to candidiasis, trichomoniasis and /or bacterial vaginosis.

The likelihood and feasibility of a provider undertaking a pelvic examination for new family planning clients is dependent, however, not only on their deciding whether it is appropriate for the presenting client, but also on their training and availability of appropriate equipment and supplies. The proportion of new family planning clients observed to have a pelvic examination varied from a low of 50 percent in Busoga, through 70 percent in Nakuru to 92 percent in Botswana ${ }^{11}$. It is encouraging to note that almost all of the pelvic examinations observed included all three components, i.e. a visual inspection of the external genitalia, internal examination through a bimanual palpation and/or a speculum examination, and were undertaken correctly. 


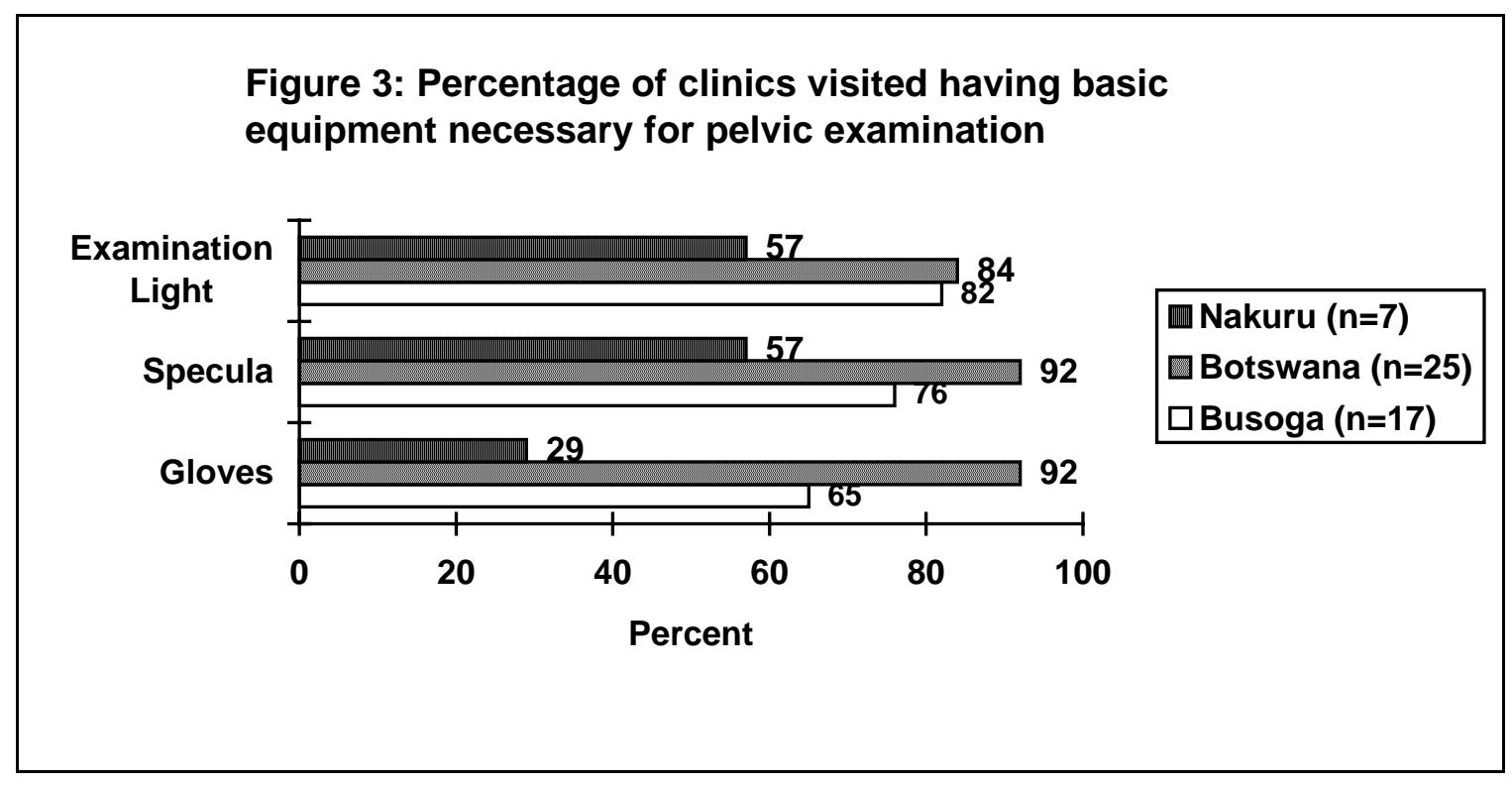

\section{b) Diagnosis of STIsb) Diagnosis of STIs}

Once the provider has established that a client has signs and/or symptoms suggestive of an STI, the expectation is that these symptoms will be correctly classified into a clinical syndrome, the client will be provided appropriate curative treatment, and partner notification / contact tracing will be undertaken to ensure treatment of their sexual partners. All four programs implement case management fairly similarly, although there are some differences due to the resources available, the policies and procedures in operation, and the sociocultural context.

All four case studies use the syndromic approach to make a diagnosis and decide treatment. This approach uses clinical algorithms, in the form of simple flow charts to identify four broad syndromes of infections, classified according to presenting symptoms and signs. It can be used, therefore, in situations where there are no laboratory testing facilities available. The national STD/AIDS Control Programs in all three countries have adapted the standard WHO algorithms (WHO, 1991) to suit local conditions, and each case study program uses its national guidelines. The major differences between the national sets of algorithms is in the types of medications recommended for treating the syndromes.

All guidelines take as their starting point the following four major symptoms and 
signs of infection which can be detected through the verbal and/or clinical examination screening procedures described above:

- $\quad$ vaginal discharge
- $\quad$ urethral discharge
- $\quad$ lower abdominal pain
genital ulcers.

It should be emphasized that these algorithms were developed for use primarily in STI clinics among clients presenting with known symptoms, and in these high prevalence populations the algorithms have acceptable sensitivity, specificity and positive predictive values $(\mathrm{PPV})^{12}$. However, when used in circumstances where the prevalence of STIs is relatively low and many of the clients are asymptomatic (e.g. for clients attending MCH/FP clinics), these values can drop substantially (Daly et al, 1994; Gertig et al, 1997).

Recent studies (e.g. Kapiga et al, 1997) show that the PPV of all four algorithms can be improved through the addition of a behavioral risk score to the information gained through the clinical history and/or examination. This score is calculated through weighting ${ }^{13}$ and summing the presence or absence of certain behaviors of the client and her partner(s) obtained during history taking and/or behavioral risk assessment. None of the case study programs currently use risk scoring as part of their detection and diagnosis procedure, but a brief review by Adler $e$ al. (1996:89-92) suggest that it is a refinement of the syndromic approach which is certainly worth exploring further.

There is an on-going debate concerning the efficacy of the syndromic approach which will not be reviewed here; the focus in this paper is on the feasibility of implementing this

12 Sensitivity describes the proportion of true positives detected by an algorithm; specificity describes the proportion of true negatives detected; and the positive predictive value of an algorithm is the proportion of cases classified as true and confirmed separately that they are truly positive. risk factors are assigned equal weights, while others use a weighting scheme based on the adjusted odds ratios for each factor derived from logistic regressions. 
approach in terms of clinical operating procedures rather than its effectiveness in correctly diagnosing and treating STIs. It is important for the future planning of these programs that attention be paid to this debate, however, as all four programs decided to use the syndromic approach because it is recommended by their national health programs. Each country $\mathrm{s}$ $\mathrm{MOH}$ and the donors supporting their programs have judged it to be the most appropriate strategy for their situation, i.e. limited availability and access to laboratory facilities and trained staff, and a perception that there is a relatively high prevalence for many STIs amongst family planning and antenatal clients. Its efficacy given a high proportion of asymptomatic cases, whether it is cost-effective, and whether there are ethical considerations given the potential for over-treating uninfected patients remain debatable issues, however.

The case study methodology provides a snap-shot of the way in which each program operates over a very limited period of time, and so only a small number of family planning clients were observed to be managed for a suspected STI, thus limiting the opportunity to assess the provider s competence in case management. In Busoga, 18 clients of the 66 consultations observed had symptoms and/or signs suggesting an STI. Using the syndromic approach the service providers classified 13 of them as having the lower abdominal pain syndrome and treated them accordingly; the remaining five cases were referred to another facility for further investigation.

In Nakuru it was possible to review the records of all clients diagnosed and treated for STIs using the syndromic approach at the five MCH/FP clinics. Over a one year period the lower abdominal pain syndrome was the most common diagnosis (44 percent) followed by vaginal discharge (34 percent) and genital ulcers (21 percent). It is discouraging to note, however, that for the twelve STI clients observed at the Nakuru STI clinic, the providers did not carry out a full risk assessment, obtain adequate history, carry out a general or pelvic examination, or follow the diagnostic algorithms correctly, despite the fact that during their training, most emphasis had been placed on this aspect of STI management, and the algorithm flow charts were on the clinic walls.

It had been anticipated that the case study methodology would only provide a few examples of women being detected and diagnosed for potential STIs, and so an alternative 
approach to assessing provider competence in managing a suspected STI case was used. Providers in Busoga and Nakuru were asked which additional information they would normally seek from a woman presenting with visible symptoms of a vaginal discharge, one of the four STI syndromes; the results are presented on Figure 4.

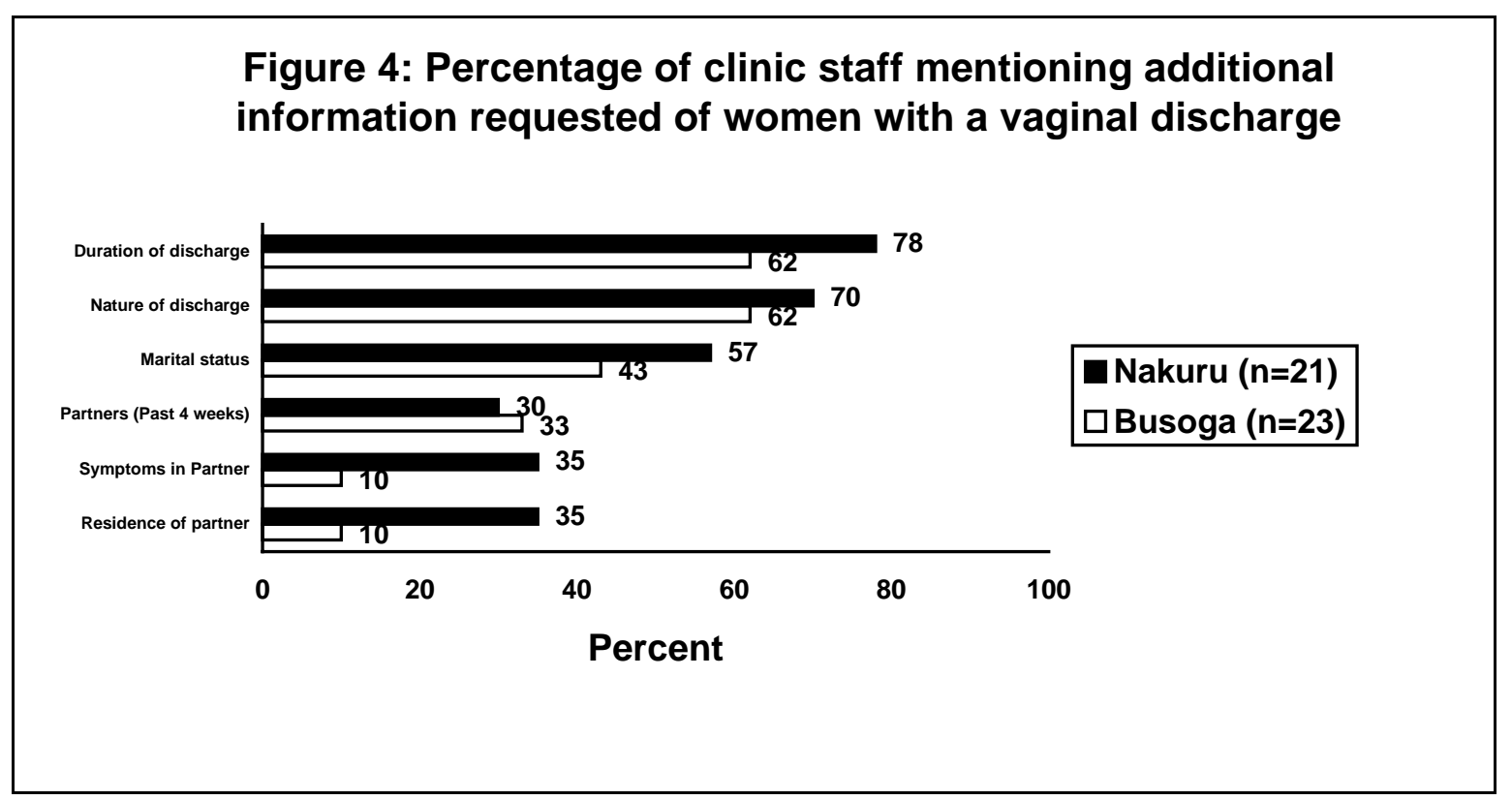

These data suggest that many of the providers either do not know that they should be asking additional risk assessment questions to assist in diagnosis and treatment (which would suggest a weakness in their training), or if they do know about asking them they are not routinely asking clients presenting with STI symptoms. It is clear that they tend to focus more on the woman s immediate symptom than on her and her partner(s) behavior.

Although all four programs expect their staff to use the syndromic approach to make a diagnosis and to determine treatment, the Nakuru program has ready access to a specialist STI laboratory and both Mkomani clinics have on-site, albeit limited, laboratories. Consequently, some use of these laboratory facilities is made. For example, in the Nakuru program, clients with STI symptoms are first treated following the syndromic algorithms and clients who do not respond to the first treatment within seven days, or those clients with complicated symptomatology are referred to the STI laboratory. 


\section{c) Treatment of STIsc) Treatment of STIs}

Each of the four programs expect their staff to follow the national STI treatment guidelines for each syndrome. In almost all cases, however, staff appear unable to follow these guidelines. Some staff could not describe to interviewers the drugs recommended to treat specific syndromes, suggesting that their training had been inadequate and/or that they needed to have some written reminders available in the clinic. Service provider guidelines were missing at nearly all the facilities visited.

The regimens recommended by the national STI control programs are changed from time to time due to changes in drug sensitivity, but these changes are not always reflected in the algorithms and service providers manuals because revising and distributing the new algorithms takes time. For example, in Kenya the current service provider guidelines were developed more than three years ago and yet several changes have taken place in the management of STIs since. In Botswana, the guidelines were revised in 1994 but had not been distributed by June 1996.

For the Busoga and Mkomani programs, run by NGOs, insufficient funds and ineffective cost-recovery mechanisms mean that the program managers cannot afford to purchase the nationally recommended drugs and so purchase others instead; the Busoga program also suffers from frequent drug stock-outs. Consequently, staff either prescribe alternative drugs if they are available at the clinics or send their clients to a pharmacy to buy the drugs themselves. Neither strategy is completely acceptable as the former may result in the use of an ineffective treatment, and the latter in low-income women not obtaining treatment at all if pharmacy prices are perceived to be too expensive.

The Nakuru program, although a public-sector program, had special donor funding available for the purchase of recommended drugs at the time of the case study. While this made it possible for staff to follow the guidelines and not to charge clients, it also created a situation where these drugs were reserved explicitly for STI treatment. Consequently, although staff were working in an integrated delivery system, they became frustrated because these same drugs could be used to treat other problems, for which there is an acute 
shortage of drugs. Subsequently the program has now started a cost-recovery mechanism using drugs donated from the UK Department for International Development for STIs and other conditions.

The Botswana national program is probably fairly unique in sub-Saharan Africa in that the program is relatively well-financed and has a functioning commodity logistics system (supplying family planning and STI commodities together) which means that drug supply is not a problem.

In Kenya (as in many other countries in the region), the national Drug and Poisons Act does not allow nurses to prescribe certain categories of drugs, including antibiotics used for STI treatment. Thus despite their training in the syndromic approach, nurses at the Nakuru and Mkomani programs are not allowed to prescribe drugs for treatment and instead have to refer their clients to a clinical officer or doctor who then relies on the nurses diagnosis to prescribe medication. This policy clearly limits the potential for any STI control program being implemented in clinics where a nurse is the only provider available, and requires the client to undertake a second consultation to complete treatment. This and similar Acts in Kenya are currently being reviewed with the hope that the regulations will be changed.

\section{d) Contact tracing through partner notificationd) Contact tracing through partner notification}

Acting on the assumption that a woman diagnosed as infected will almost certainly have one or more infected partners, all four programs make efforts to trace the women $\mathrm{s}$ sexual contacts. Given the limited resources available, contact tracing through home visits and referral by the clinic-based staff is clearly not a feasible option, although the Mkomani and Busoga programs did briefly try partner notification through the clinics community outreach workers. This quickly proved impossible for two reasons. First, the women did not want anyone else to know about their treatment or to communicate with their partners about 
their infection, and so resented the idea that someone else would be contacting their partners. Second, the outreach workers in both programs, but particularly in Busoga, are related to or friends with a significant proportion of the clinic clientele, and they did not feel at all comfortable discussing these issues with someone who is either their relative or friend. They were particularly concerned about the dilemma facing them if the woman and her partner(s) had not already discussed the infection, or if the sexual partner was not the regular partner ${ }^{14}$.

Because of the difficulty in operationalizing a provider referral system, the four programs expect staff to encourage the clients to notify their partner(s) themselves, and to encourage them to seek treatment. Identification of the contact, however, is not made a prerequisite for receiving treatment in any of the programs. All four programs rely primarily on verbal notification, but asking women to notify their partners verbally has proved to be very difficult. This would seem to be because women are afraid to discuss such infections with their partners, despite the fact that in the vast majority of cases it was probably the male partner who was initially infected ${ }^{15}$. The Nakuru and Busoga programs have tried giving written notes to the woman to pass on to her partner, but in general this has not worked very well, although some married women have requested such notes as it avoids the need for them to discuss the issue directly with their partner. In these two programs prescriptions and/or medications for the partner are sometimes given to the client without requesting that the partner comes to the clinic.

To illustrate this point, clients in Busoga were asked what they felt about discussing STIs and sexual behavior with providers and with their partners. The overall levels of discomfort were uniformly high, ranging from 45 - 63 percent of clients feeling uncomfortable discussing either topic with anyone. Overall, clients were slightly more likely

14 Studies in Nigeria and Zimbabwe undertaken in the 1980s have shown differing levels of effectiveness for referrals made by providers. The Nigeria study reported that home visits by clinic staff added very few extra partners attending for treatment beyond those notified directly by their partners, whereas the Zimbabwe study showed that home visits by community health workers could bring in more than half as many partners again (reported in Adler et al. (1996:86)). women, over two-thirds said that they had been infected by their spouses (Moses et al., 1994). 
to feel uncomfortable discussing sexual behavior than STIs, and to feel more uncomfortable discussing these issues with staff than with their spouse.

Unfortunately, staff themselves do not routinely inform clients of the importance of partner notification. For example, of the 14 clients observed to be treated for STIs during the Nakuru case study (12 at the STI clinic and 2 antenatal clients), only three were advised about partner notification, and in Busoga, of the 13 antenatal clients observed to be treated for an STI, only three were told about partner notification. Furthermore, in the Busoga and Botswana case studies, only 17 percent and 13 percent respectively of clients observed being given general counseling about STIs were told of the importance of partner notification.

Empirical evidence of the effectiveness of these contact tracing mechanisms is generally lacking because only the Nakuru program keeps records of contact tracing. All clients treated for STIs are given a "contact slip" bearing their name to give to their partner, and if the contact returns to the clinic he is expected to present the slip which is then linked to the primary contact in the service statistics. Although not perfect as there is inevitably some under-reporting due to returning contacts not being recorded in the service statistics, this approach has been found to be feasible and helpful to program managers. It does, however, compromise clients confidentiality which may contribute to the low return of contacts $^{16}$.

Figure 5 describes the contact rate for female clients treated for different STI syndromes at the five Nakuru MCH/FP clinics. Overall, for approximately 10 percent of women treated for lower abdominal pain, vaginal discharge or genital ulcers, their partners were notified and treated. Among the antenatal clients diagnosed and treated for syphilis the proportion was over one third, but it should be noted that only 31 women were treated. Given the perceived psycho-social difficulties of partner notification and the apparent reluctance of staff to emphasize its importance, ten percent may be a good return rate, but

$16 \quad$ Following this case study, the program has revised its contact slips to remove the clients name and is instead using coded numbers to maintain anonymity for the client while still allowing the program to track contacts. 
this means that 90 percent of women treated are likely to remain at risk of re-infection in the near future by their partners, thus effectively negating the treatment received.

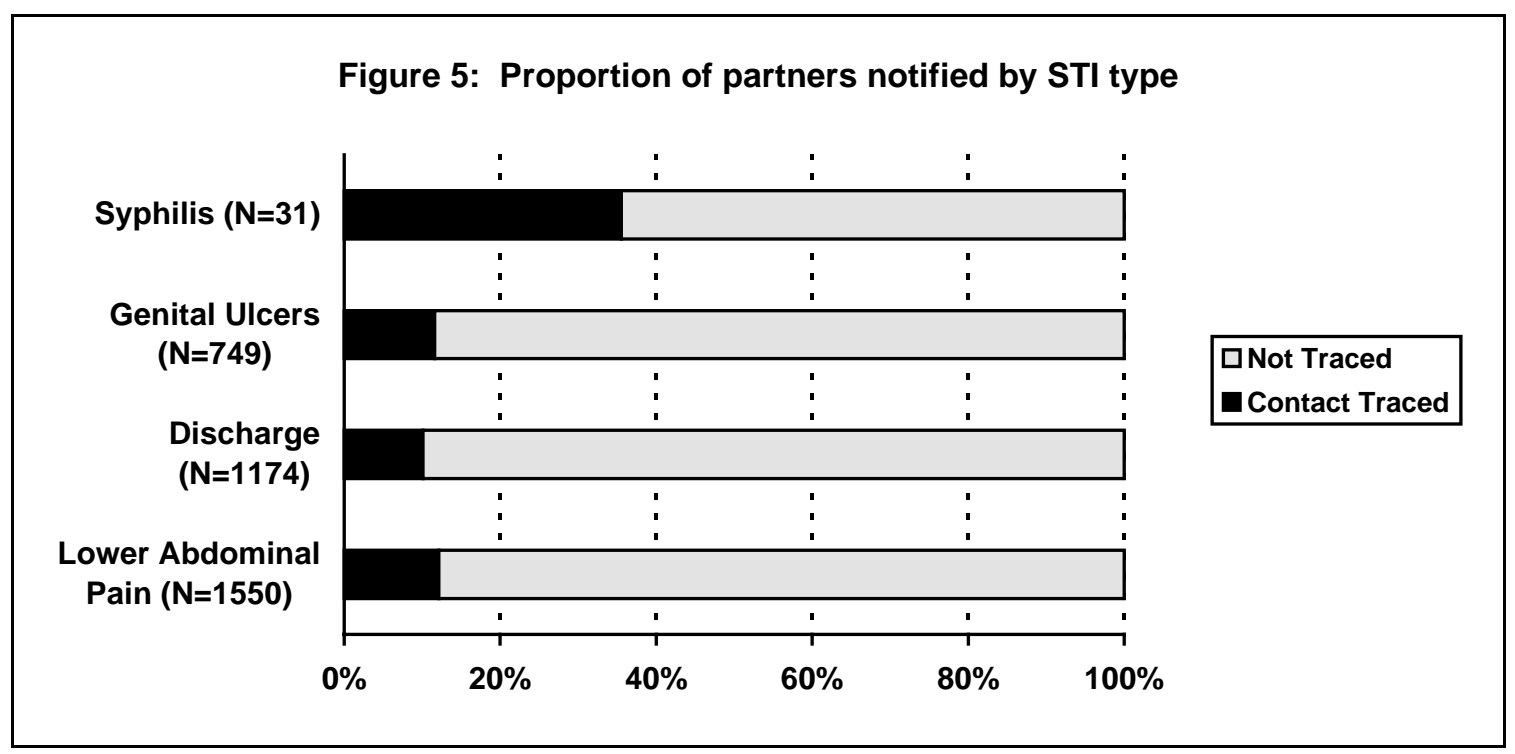

In their review of partner notification strategies, Adler et al. (1996:87) conclude that:

low rates [of partner notification] can be improved by $20-50$ percent by addressing the following:

i. $\quad$ training staff to counsel patients about partners;

ii. introduction of contact cards or coupons;

iii. incorporation of information about the importance of partner referral and STI symptoms in health education materials and interventions;

iv. lowering the cost of treatment and improving access to services.

\section{e) Counseling and testing for HIV/AIDSe) Counseling and testing for HIV/AIDS}

Two STIs in particular have been singled out by all four programs for special attention: HIV and syphilis. All four programs serve populations where the prevalence of $\mathrm{HIV}$ is high and the major mode of transmission among women attending MCH/FP clinics is heterosexual intercourse; consequently, HIV counseling and testing are seen as essential components of any STI control program being implemented within MCH/FP clinics.

Almost all providers indicated that they have received training in general HIV/AIDS 
counseling, usually through in-service refresher training as one component of the overall integration intervention. So, in theory, they are able to inform and educate clients about HIV transmission and symptoms. However, issues related to HIV/AIDS were infrequently discussed with clients observed receiving $\mathrm{MCH} / \mathrm{FP}$ services, and there was, moreover, a wide range across the programs - from three percent of clients in Nakuru, through one quarter in Busoga to over half the clients in Botswana.

Managers for all four programs feel, however, that HIV testing (and its associated counseling) is both difficult and sensitive, and is beyond the capacity of their standard $\mathrm{MCH} / \mathrm{FP}$ clinics and staff. Consequently, all four programs have made arrangements for

clients who exhibit signs and symptoms of HIV/AIDS, or who specifically request a test, to be referred elsewhere for testing and its associated counseling. Thus the Mkomani clinics have established a referral arrangement with the Provincial hospital in Mombasa, and the Nakuru clinics refer their clients to the Provincial hospital in Nakuru, whereas the Busoga program relies on the services of another NGO, the AIDS Information Center (AIC), to do HIV testing and counseling through its mobile clinics. In Botswana, HIV testing facilities are available at only five percent of the health facilities and these are mainly hospitals. Clients attending other facilities and needing HIV testing have their blood specimens taken at the clinic and sent elsewhere for testing.

This referral process has its own problems, however. For example, in the Busoga program staff report that after referral to AIC for testing, many clients never come back to seek further support and assistance. In Botswana, results of the HIV test take on average 18 days to be received back at the referring center, thus delaying counseling.

\section{f) Screening Antenatal clients for syphilis) Screening Antenatal clients for syphilis}

Virtually all STIs are known to have an adverse effect on pregnancy outcomes (Wasserheit \& Holmes, 1992; Schulz et al, 1992; Elias, 1991:10); indeed it can be argued 
that the problems caused by RTIs are at least as serious as those caused by the immunizable diseases (Schultz et al, 1992). Of the major STIs, however, the only one for which detection and treatment in women attending for an antenatal checkup is strongly recommended is maternal syphilis; for gonorrhea and chlamydia, the current opinion is that prophylaxis in the newborn is a more cost-effective intervention than detection and treatment in the mother during pregnancy ${ }^{17}$ (see Schulz et al. (1992) for a detailed discussion). Studies have shown that amongst pregnant women with early syphilis, 20-25 percent will lose the fetus, 15-50 percent will deliver low birth weight or premature babies, and 40-70 percent will pass on a congenital or perinatal infection (Wasserheit and Holmes, 1992). Infection rates for syphilis amongst antenatal clients in sub-Saharan Africa generally are in the range of 4-15 percent (Schulz et al, 1992).

These factors have convinced policymakers in several African countries, including Kenya, Uganda and Botswana, to recommend that syphilis testing be provided for all antenatal women attending MCH/FP clinics. For these reasons, all four programs include antenatal syphilis testing as one component of their integrated approach. The case studies reveal many difficulties in trying to implement this recommendation, however.

The Botswana MOH uses the VDRL test to screen for syphilis, which requires fairly sophisticated laboratory facilities, and so although syphilis screening is available at $95 \%$ of the hospitals it is only available at fewer than $10 \%$ of other levels of service delivery, which is where most clients attend. Blood samples have to be sent from these clinics to a referral laboratory, a service which takes an average of five days. However, the MCH/FP program management estimates that 90 percent of antenatal clients are tested, although the proportions receiving results and treatment are not known.

In the Nakuru program, the donor agency made available the necessary equipment and supplies to screen for syphilis using the simpler, but less specific RPR test at the reference laboratory. In 1995, a little over half of approximately 9,000 new antenatal substantial impact on prematurity and perinatal mortality. 
clients from the program s five clinics were screened for syphilis. Blood specimens are collected from the women at the clinic attended for antenatal care and sent to the reference laboratory for testing. Of the 4,577 women tested, 0.7 percent ( 31 women) tested positive; however, only 18 of these 31 women and 11 of their partners actually received treatment ${ }^{18}$.

For the Mkomani program, antenatal clients are routinely referred from the consultation room to the on-site laboratory at each clinic for a VDRL test. In 1994, of the 1,500 new antenatal clients seen, 27 percent had themselves tested. Of these 398 women tested, 4.5 percent (18 women) were found to be positive.

Moreover, the program s cost recovery scheme means that women are charged for the test and this is perceived by the staff interviewed to be the main reason why threequarters of antenatal clients decided not have the test. A willingness to pay study is needed to validate whether this is indeed the case or whether there are other factors inhibiting women from taking the test.

None of the clinics in the Busoga program have syphilis testing facilities, and so providers are expected to refer clients to the nearest Government facilities. Only a handful of providers said that they did this and none of the antenatal clients observed during the case study were referred. Unfortunately, the program records do not keep statistics on syphilis screening.

The reasons why this is an ineffective service are fairly clear. For the Botswana and Busoga programs, an extra visit to the clinic is required to obtain the result at a later date; indeed, for the Busoga program, the blood sample and result are undertaken at another clinic, thus requiring two extra visits to a different clinic. In the Nakuru program the referral laboratory is in close proximity to the clinics, but clients cannot get their results during the same clinic visit because it still takes a few days and so they have to return later ${ }^{19}$. This

18 A single dose therapy with benzathine penicillin. as five minutes after the specimen has been collected. If the sample has to be sent to an off-site 
clearly deters women from both taking the test and returning for the results, as evidenced by the 48 percent of clients who did not take the test, and the 42 percent of positive cases detected who did not return to find out the result or to be treated. For the Mkomani clinics, the test is done on-site but the results are not available the same day.

\section{2) Prevention of new infections and improving health-seeking behavior5.2) Improving health-seeking behavior and prevention of new infections}

All four programs would like to prevent new infections amongst partners and others and to improve the health-seeking behavior of those clients who feel they may be at risk of, or actually are, infected, but these appear to be their weakest components. This is not surprising as any type of behavioral change intervention that goes beyond the client herself is generally difficult for a clinic-based program to implement. Essentially, the programs rely on limited clinic-based and community-based IEC activities with some promotion of condom use.

\section{a) Information and education in the clinicsa) Information and education in the clinics}

All programs have sought to inform and educate $\mathrm{MCH} / \mathrm{FP}$ clients attending their clinics about STIs and HIV/AIDS. Indeed, of all the clinics visited for all four programs, only one clinic (in the Busoga program) did not provide HIV/AIDS information ${ }^{20}$. The IEC activities include a combination of reviewing the topics during group health talks, having print materials available, and discussing them with clients during individual consultations.

laboratory, however, even if it is close by there will be a need for a return visit by the woman or at least a delay in getting the result to her. If the woman is returning for a second antenatal visit within a short time period then the result (and treatment if necessary) could be given at that time. percent and 29 percent of the Botswana and Busoga clinics respectively. 
The extent to which these IEC activities are actually carried out seems to vary between the programs, however.

Group health talks for clients before services commence in the morning are mandatory in all four programs, but it appears that they are not held regularly. Furthermore, when they are held, the topics of HIV/AIDS and STIs are rarely included. The Busoga program performed best in this regard, where health talks were held in 10 of the 17 clinics visited and all ten talks included discussions of family planning, STIs and HIV/AIDS. Group health talks are held so that women have an opportunity for some basic health education in addition to the service for which they are attending, and are intended to be interactive so that questions can be asked to clarify certain topics. As such, they would seem to be a potentially cost-effective mechanism for communicating messages about infection prevention and diagnosis and treatment of infection symptoms. As has been seen in these case studies and in numerous Situation Analysis studies from other African countries, however, the group health talk is a neglected IEC intervention which would benefit from further attention and evaluation ${ }^{21}$.

Traditionally, MCH/FP clinics have tended to rely on printed materials for communicating health messages while women wait for their consultation and during the consultation itself. Posters, flipcharts and brochures were frequently not present in all clinics, and where they were present, they were often not particularly informative. Obviously such materials need to be tailored to the literacy levels and culture of the clients, which can be difficult when these same materials are expected to be used in both urban and rural settings and even across different countries. The effectiveness of using print materials in communicating reproductive health messages is not well known ${ }^{22}$ and this issue may need to be explored further in relation to the sensitive and stigmatized topics of STIs/HIV/AIDS before any recommendations can be made as to whether more effort needs to be made in promoting their development. group health talks would be more effective, perhaps through the provision of a set of guidelines and materials to help staff prepare for and give the talks. proportion of the population, probably because of frequent visits to clinics (.Kim et al., 1996). 
A key opportunity to provide information on STI and HIV/AIDS prevention, diagnosis and treatment is during the individual consultations with family planning and antenatal clients. A full assessment of a client $\mathrm{s}$ family planning needs should include gathering information about their sexual behavior, partner relationships and experience of STI symptoms so that an appropriate and non-contraindicated method can be chosen. In doing so the provider will also have the chance to give the client information that could reduce new infections and improve treatment in the case of future infection. All four programs explicitly encourage their providers to discuss STIs and HIV/AIDS with their family planning clients.

Data on this are available and the results are mixed but somewhat encouraging. For the consultations observed, 53 percent of the MCH/FP clients in the Botswana clinics and 62 percent of those in the Busoga clinics received information on STIs and/or HIV/AIDS, but only four of the 60 clients observed in the Nakuru clinics (i.e. seven percent) received this information. Figure 6 describes the main topics covered during the Botswana and Busoga observations, showing that condom use and risk factors tend to be the issues most frequently discussed. As highlighted earlier, more attention needs to be placed on describing potential signs and symptoms and stressing the importance of partner notification if a woman is infected.

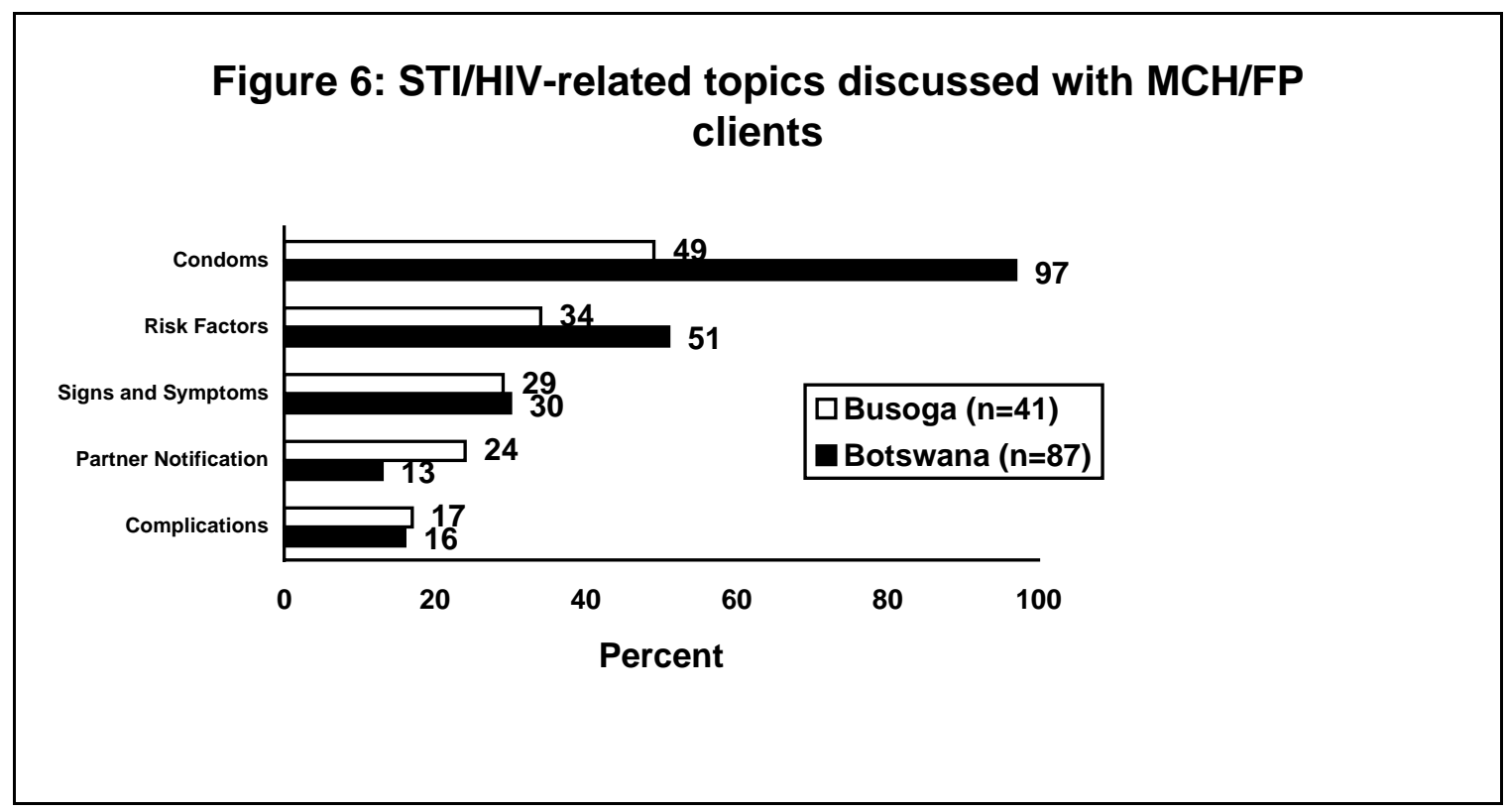


The emphasis placed by providers in different programs on the use of the condom appears to be reflected somewhat in their clients perceptions of how best to prevent infection, as shown in Figure 7. While clients in Busoga clearly place more emphasis on reducing the number of sexual partners by practising fidelity, the use of condoms appears to be the preferred strategy in Botswana; in Nakuru, both approaches are seen to be important. These differences may also reflect larger socio-cultural differences in beliefs about sexual behavior between the three populations and about the efficacy of condoms.

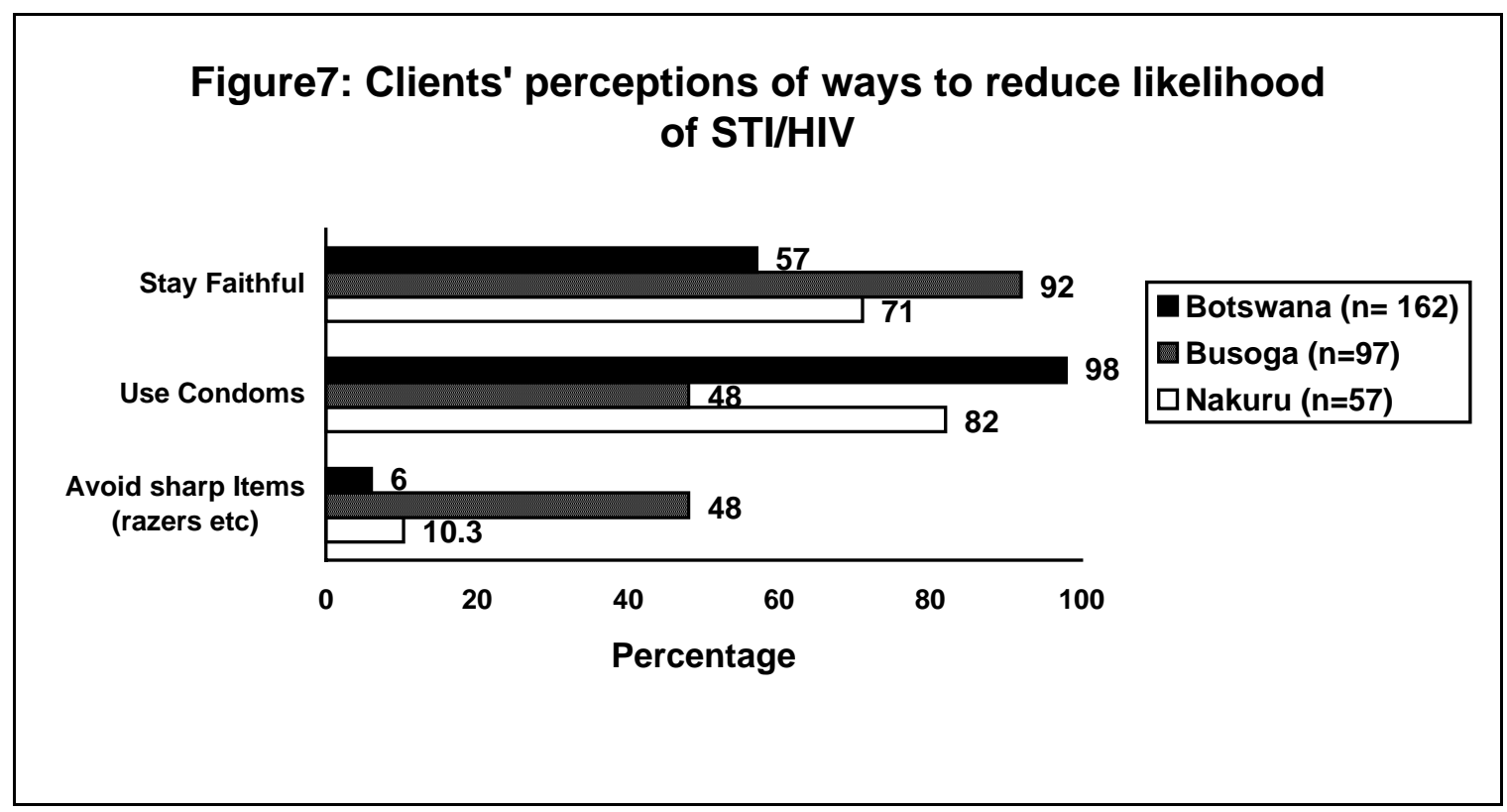

Rather surprisingly, the provision of information on infection prevention to $\mathrm{MCH} / \mathrm{FP}$ clients who have been detected, diagnosed and treated as having an STI is weak. For example, of the 13 antenatal clients in the Busoga program treated for an STI, very few were observed to be given any information concerning the infection and, more worryingly, how to prevent further infection in the future. Only six were told of ways to protect themselves, with four being told about condoms, and only seven were told to notify their partner. Similarly, in Nakuru of the 12 clients treated for STIs, only two were informed about condoms and three about partner notification. Clearly, this is a weakness which could and should be corrected.

b) IEC activities in the communitiesb) IEC activities in the communities 
The Botswana national $\mathrm{MOH}$ program is primarily clinic-based, but at the community level there are "health posts" which are staffed by Family Welfare Educators (FWEs) whose primary role is to educate families and communities about health issues and to motivate them to use health services; in rural areas they are seen as the first point of contact with the health care system. Although almost all of the 163 FWEs interviewed had been trained in child welfare and family planning and about one half in antenatal care, only one third indicated that they had received training in STI management and less than 10 percent had been trained in HIV/AIDS. Clearly there is a need to further strengthen the ability of the FWEs to provide information on infection prevention and to act as a referral for treatment of suspected cases if the integrated approach is to characterize the whole health care system.

The other three programs have established community-level outreach IEC activities in their clinic catchment areas which focus on family planning, STIs and HIV/AIDS. The Mkomani and Busoga programs already had strong community-based IEC activities organized around community workers who promoted family planning and provided nonprescription contraceptives. These take the form of home visits, group talks, school visits and addresses at other public meetings by the community-based outreach workers and occasionally by the clinic staff ${ }^{23}$. With the introduction of each program $s$ integration initiative, concerted efforts have been made to broaden the range of messages communicated so that STIs and HIV/AIDS are explicitly included.

The Nakuru program operates in an area with a large population of commercial sex workers (CSWs) for who fertility regulation and infection prevention are seen as important concerns. The program has recruited peer educators from amongst the CSWs and trained them to provide information on STIs, HIV/AIDS and MCH/FP services to other CSWs and to assist CSWs wishing to develop alternative means of generating income. The program also has a team of counselors who visit schools and industrial workplaces to provide information and counseling, and non-prescription contraceptives including condoms. culturally appropriate plays and songs with messages on STIs, HIV/AIDS and MCH/FP themes. These plays and songs are performed to audiences within the communities during various communal events. 
Through their community-based approaches, all three programs have been able to reach a wide range of audiences, including the high risk groups of youth, CSWs and men. Moreover, the community workers in all three programs report being better received now by their communities due to the broadening of their activities beyond family planning and the perception that they are responding to the communities health needs in a more comprehensive manner.

\section{6) A prototype model for integration?6) A prototype model for integration?}

Although all four models were developed independently, operate within different organizational and socio-cultural environments, and serve different populations, a number of commonalities are apparent in the way in which the services have been organized. The box on the next page summarizes what appears to be a fairly standard model emerging from these case studies, although no one program was found to have all of these components. Five points need to be highlighted.

First, the activities described in the model are feasible and applicable for MCH/FP clinics which do not have on-site facilities that would permit even basic STI testing. As lowcost STI tests emerge that could be used in such situations, the approach to case detection among asymptomatic women would also change.

Second, the case detection procedures described are applied primarily to new family planning clients and, to a lesser extent, to first visit antenatal clients. History taking and a clinical examination are integral parts of these services and so the additional case detection activities have been added fairly easily. Whether case detection through risk assessment, history taking and clinical examination can, and should, be extended to revisit family planning clients, later-term antenatal clients, and clients attending for infant or child welfare 
services needs further consideration given the implications for additional resources and time spent with the client.

Third, most attention has been paid by program managers to integrating the detection and treatment of STI cases amongst asymptomatic women attending their clinics for $\mathrm{MCH} / \mathrm{FP}$ services. Integrating communication and behavior change that encourage infection prevention and improved health-seeking behaviors activities into existing MCH/FP IEC strategies are clearly essential components of any model for providing integrated services and need to be strengthened.

Fourth, although not a major focus of the case studies, anecdotal evidence suggests that this integrated approach is acceptable to both providers and clients because additional services are provided in a way that reduces overall time for the client and jointly providing the services does not unduly burden the provider ${ }^{24}$. Empirical evidence of the actual time and costs involved in providing integrated compared with vertical services is needed within the framework of an overall cost analysis. Moreover, because STI/HIV services are more sensitive than $\mathrm{MCH} / \mathrm{FP}$ services and their users are usually stigmatized, it is clear that particular attention needs to be paid to the way they are presented within the clinic environment.

Fifthly, the cost of providing these services was not included in these case studies and is the subject of a complementary study being implemented by REDSO/ESA. Cost analyses have been undertaken of the Botswana, Mkomani and Busoga programs and are reported in a forthcoming monograph.

As is apparent from the results of the case studies, this model does not appear to be functioning optimally at present. Some reasons for this are specific to the particular situation of each program; indeed, following the case studies a number of programmatic changes have

24 Staff in the Busoga program felt that there had actually been an increase in the use of MCH/FP services because they were now being provided in a broader reproductive health context which made them more attractive. 
been made by program managers ${ }^{25}$ based on these observations. The concluding section which follows, therefore, makes some broad programmatic recommendations as to how such a model of integration could best be implemented, and suggestions are made for further research on those issues which the case studies could not address.

25 The reports for the Mkomani (Twahir et al., 1996), Busoga (Mukaire et al., 1997) and Nakuru (Kariba et al., 1997) case studies include descriptions of the problems identified and the remedial actions by the program managers. 


\section{A prototype model for integrating STI/HIV Services into MCH/FP Programs}

Applicable for MCH/FP clinics with no or limited access to laboratory facilities Integrated service offered primarily to new family planning and antenatal clients Package of services offered at single visit

Four components of STI control added to FP/ANC services:

1) Case detection and treatment of asymptomatic women or women not recognizing existing symptoms, through:

- $\quad$ risk assessment by asking questions on behavioral factors

- clinical history taking

- general clinical examination

- pelvic exam if possible (full preferably)

- $\quad$ if signs/symptoms identified, categorize into general syndrome

- $\quad$ provide appropriate curative treatment, on site, preferably by same person doing diagnosis, and at same time as diagnosis

- encourage contact tracing through partner notification by client

2) HIV/AIDS management through:

- $\quad$ HIV testing and counseling through referral to nearest specialist site for clients with signs and symptoms, or for those explicitly requesting testing

- IEC on prevention of HIV transmission and signs/symptoms of HIV infection to all clients

3) Detection and treatment of maternal syphilis through:

- $\quad$ screening all antenatal clients on first visit for syphilis infection through referral for test and/or result

- encourage contact tracing through partner notification by client

4) Information and education to prevent new infections and to improving health- seeking behavior if infected through:

- raising awareness of signs and symptoms of possible infection

- education on safer sexual behavior and practices

- promotion of condom use

- group health talks

- print materials available in waiting rooms, during individual consultations and to be given to clients

- $\quad$ individual consultations with MCH/FP clients

- group and individual talks within the clinic catchment areas through community health workers including STI/HIV with MCH/FP messages

- $\quad$ advertising availability of services 


\section{7) Lessons learned, recommendations for programme}

strengthening and suggestions for further research7) Lessons learned, recommendations for programme strengthening and suggestions for further research

\section{Little accurate data are available to inform program managers as to which diseases are most common among their clientele, and so managers do not know what level of service utilization rates to expect or the requirements for ordering drugs.}

$\Rightarrow \quad$ Wherever possible, population-based surveys of reproductive morbidity, and especially STI prevalence, should be undertaken by program managers prior to developing integrated programs. Ideally these would use inexpensive bio-assay tests ${ }^{26}$, but well-designed questionnaire surveys could also be used subject to further validation.

Research: feasibility of population-based measures of STI/HIV prevalence, including validation of questionnaire surveys on reproductive morbidity and improvement of simple bio-assay tests

Research: $\quad$ utility of facility-based measurement given selection biases of population attending clinics

Risk assessment and clinical history taking are essential components of detecting STI cases among mainly asymptomatic MCH/FP clients but is not performed consistently or according to guidelines.

$\Rightarrow \quad$ Train clinic staff in sexuality counseling and in being more aware of clients self-assessment of risk

$\Rightarrow \quad$ Develop service delivery guidelines that take into account the sociocultural situation of staff

$\Rightarrow \quad$ Provide clear written guidelines and checklists for clinic staff to follow their application through population surveys is equally important. The DHS pilot-tested an approach in Ethiopia with promising results (Macro International, 1997). It should be noted that although the specimen collection is quite simple, and appears to be acceptable, transporting the specimens for testing remains a substantial logistical, and expensive, task. 
that specify exactly which questions to ask and how to interpret the answer

$\Rightarrow \quad$ Ensure guidelines are reviewed and updated regularly, preferably based on observations of staff performance and validation studies

$\rightarrow \quad$ Redesign $\mathrm{MCH} / \mathrm{FP}$ client record cards to record data for risk assessment and STI clinical history

$\Rightarrow \quad$ Improve levels of privacy available during consultations.

Research: comparison of time taken to undertake normal $M C H / F P$ client consultation with one that includes comprehensive risk assessment and clinical history taking

Research: acceptability of an integrated consultation from the provider, client and clinic manager s perspectives

Research: clients and providers attitudes towards discussing sexual and STI issues in clinic environment

Research: factors and weights to include when including scoring within a risk assessment

Clients awareness of symptoms and signs associated with STIs, their ability to identify and describe them, and the providers capacity to understand clients descriptions need to be improved for the syndromic approach to work effectively.

$\Rightarrow \quad$ Increase clients awareness of symptoms and signs through IEC activities within clinics and, where possible, through community-based programs

$\rightarrow \quad$ Train staff in local terminology and concepts used to describe potential signs and symptoms

Research: $\quad$ document perceptions, definitions and descriptions of reproductive morbidity in catchment area populations

Research: $\quad$ test IEC interventions in clinics and through outreach programs to raise awareness of symptoms and signs among general population. 


\section{A thorough general clinical examination and a pelvic examination, essential for detecting signs and symptoms associated with STIs, are not always undertaken.}

$\rightarrow \quad$ Reinforce amongst staff the need for a thorough general physical exam to assist in detecting non-genital symptoms

$\rightarrow \quad$ Ensure that client record cards are able to record all information needed for a general physical examination.

$\Rightarrow \quad$ Ensure that all MCH/FP clinics have the basic equipment and supplies needed for an internal pelvic examination (e.g. speculum, gloves, adequate light) and that there is sufficient privacy for the examination

$\Rightarrow \quad$ Train staff in providing appropriate psychological support to reduce nervousness

$\Rightarrow \quad$ If these conditions are met, reinforce the requirement that an internal pelvic examination be undertaken for all new family planning clients, annually for all returning family planning clients, and for all MCH/FP clients with symptoms and signs associated with STIs and/or assessed to be at risk through the risk assessment / clinical history taking.

The syndromic approach has been adopted because of its applicability in situations when laboratory testing is not possible, but it has not always been correctly applied.

$\Rightarrow \quad$ Program managers should constantly monitor new developments in syndromic approach procedures and update their guidelines regularly

$\Rightarrow \quad$ Whenever guidelines are updated the new information should be passed on immediately to staff through appropriate means (e.g. circulars, inhouse refresher training)

$\Rightarrow \quad$ To increase efficiency, the person undertaking the detection and diagnosis of potential STI cases should also be able to prescribe and provide treatment during the same visit.

Research: $\quad$ test and validate the syndromic approach amongst $M C H / F P$ populations and in areas with different STI prevalence levels 
Research: $\quad$ test the feasibility and effectiveness of adding risk scoring to the syndromic approach.

Most MCH/FP clinics do not have laboratories on-site and so refer less straightforward cases to facilities with laboratories, but current referral arrangements are time-consuming and frequently lead to losing the client before diagnosis and/or treatment are complete.

$\Rightarrow \quad$ Existing referral arrangements need to be examined closely to look for ways to improve their effectiveness

$\Rightarrow \quad$ As simpler screening tests become available programs should develop the capacity to use them at an increasing number of secondary and even primary level facilities.

Research: $\quad$ test the feasibility and effectiveness of introducing simple STI testing facilities (e.g. microscopy equipment and supplies, staff training, RPR tests) at MCH/FP clinics.

The syndromic approach is intended to simplify treatment of STIs by requiring a small range of drugs that can treat several types of infection, but the supply of these drugs at clinics and their purchase by clients are major problems in all but the strongest programs.

$\Rightarrow \quad$ Improve staff understanding of the different treatments available (through training and written guidelines) and update regularly to reflect changes in drug sensitivity

$\Rightarrow \quad$ Strengthen existing drug supply mechanisms and forecasting / ordering procedures for $\mathrm{MCH} / \mathrm{FP}$ clinics to include drugs that can be used for treating STI syndromes and other illnesses, and to ensure that essential drugs are routinely available at clinics

$\Rightarrow \quad$ Ensure that sufficient funds are available to program mangers, through government or donor sources or cost-recovery mechanisms, to maintain a continuous supply of drugs to the clinics

$\Rightarrow \quad$ Wherever possible, ensure that the client receives / purchases the drugs at the same clinic to ensure correct treatment provided

Research: Ascertain the willingness of clients to pay for STI services when provided during an MCH/FP consultation 
Research: $\quad$ Test the elasticity of demand associated with varying drug prices

Research: Test alternative cost-recovery mechanisms

Contact tracing is essential to treat the clients partner(s) and to prevent reinfection in the woman herself, but the procedure followed (asking the woman to notify her partner and to visit the clinic) was found to be universally weak.

$\rightarrow \quad$ Staff should make sure that partner notification is always included in the counseling given to all clients treated for an STI and whenever discussing STIs in general

$\Rightarrow \quad$ Programs should look for ways to strengthen partner notification, such as through the use of anonymous notification cards and reduced cost for partner treatment on production of a coupon.

Research: Test alternative ways of increasing contact and treatment rates for partners.

For MCH/FP clients suspected to have HIV, or who have asked for a test, all programs refer elsewhere for testing and counseling.

$\Rightarrow \quad$ Programs should review the acceptability and effectiveness of current procedures for referring clients for HIV testing and counseling to determine if they can be strengthened and whether the counseling can be decentralized to the MCH/FP clinic.

Research: As rapid and simple HIV tests become more available, test ways of introducing HIV testing and counseling into MCH/FP clinics

All programs have mandatory syphilis screening for antenatal clients but because this normally requires the client to return to the same or another site at a later date for the result and requires payment, few women have the test and even fewer return for the result.

$\Rightarrow \quad$ If programs want to continue with mandatory antenatal syphilis 
screening, then the current procedures for collecting and testing specimens, giving the result to the client, and ensuring treatment for infected clients and their partners must be examined closely to improve their effectiveness

$\rightarrow \quad$ As understanding of the interaction between antenatal infection with other RTIs (especially gonorrhea) and adverse pregnancy outcomes improves program managers should determine the cost-effectiveness of introducing antenatal screening for other STIs.

Research: Test alternative strategies for strengthening the effectiveness of the overall procedure for screening, detecting, informing and treating antenatal syphilis infections

Research: Test the cost and effectiveness of increasing the availability and use of the RPR (or other) low-cost, simple syphilis screening tests

Research: $\quad$ Test the cost-effectiveness of introducing screening of antenatal clients for other RTIs, especially gonorrhea.

\section{All MCH/FP programs mandate that group health talks should be held at their clinics daily prior to starting service delivery, but these are infrequently held and information on STIs and HIV/AIDS is only given occasionally.}

$\Rightarrow \quad$ If health talks are to continue then they need to be strengthened through ensuring that they are always held, planning which issues are to be covered, training staff in effective communication techniques and providing guidelines and materials, especially for topics such as the symptoms and signs of STIs.

Research: Effectiveness of group talks and print materials on the transfer of knowledge about STIs and family planning to $\mathrm{MCH} / \mathrm{FP}$ clients 
Condom promotion is expected to be an integral component of all information exchanges with clients, but is undertaken to differing extents by each program.

$\Rightarrow \quad$ Use of the condom for protection from STIs should be promoted more strongly, either on its own or possibly in conjunction with another contraceptive method (i.e. dual use).

Research: test the feasibility and effectiveness of different messages and supply of condoms on use and continuity of use

Research: $\quad$ assess the acceptability and effectiveness of promoting dual contraception

The availability of STI and HIV/AIDS services is not well advertised at most MCH/FP clinics which prevents clients from pro-actively coming for counseling or screening / treatment, and/or initiating discussion of STIs during a MCH/FP consultation.

$\Rightarrow \quad$ Clinic managers must ensure that clients are fully aware of all services available at the clinic, including when and where they can be obtained, through signs and posters inside and outside the clinic. Moreover, this advertising should stress that the service is available during regular $\mathrm{MCH} / \mathrm{FP}$ consultations and so does not require a separate visit, and that strict confidentiality will be maintained. 


\section{ReferencesReferences}

Adler, M., S. Foster, J. Richens and H. Slavin (1996). Sexual Health and Care: Sexually Transmitted Infections, Guidelines for Prevention and Treatment, Overseas Development Administration, London, UK.

Baakile, B., L. Maribe, B. N. Maggwa and R. Miller (1996). A Situation Analysis of the Maternal and Child Health / Family Planning (MCH/FP) Program in Botswana, Ministry of Health, Botswana and Africa OR/TA Project II, The Population Council, Nairobi, Kenya.

Brunham, R. and J. Embree (1992). Sexually Transmitted Diseases: Current and future dimensions of the problem in the Third World , pp35-58 in Germain, A., K. Holmes, P. Piot and J. Wasserheit (eds), Reproductive Tract Infections: Global Impact and Priorities for Women s Reproductive Health. Plenum Press, New York, NY, USA.

Caraël, M. et al. (1990). Research on sexual behavior that transmits HIV: the GPA/WHO collaborative survey - preliminary findings , in Dyson, T. (ed) Sexual Behaviour and Networking: Anthropological and Socio-Cultural Studies in the Transmission of HIV, Editions Derovaux-Ordina, Liege, Belgium.

Dallabetta, G. and S. Hassig (1995). Indicators for Reproductive Health Program Evaluation. Final Report of the EVALUATION Project subcommittee on STD/HIV, Carolina Population Center, Chapel Hill, North Carolina, USA.

Daly, C., B. N. Maggwa, J. Mati et al. (1994). Risk factors for gonorrhea, syphilis and trichomoniasis infection among women attending family planning clinics in Nairobi, Kenya , Genitourinary Medicine, 70:155-161.

Elias, C. (1991). Sexually Transmitted Diseases and the Reproductive Health of Women in Developing Countries. Programs Division Working Paper \#5, The Population Council, New York, NY, USA.

Germain, A., K. Holmes, P. Piot and J. Wasserheit (eds) (1992). Reproductive Tract Infections: Global Impact and Priorities for Women s Reproductive Health. Plenum Press, New York, NY, USA.

Gertig, D., S. Kapiga, J. Shao and D. Hunter (1997). Risk factors for sexually transmitted diseases among women attending family planning clinics in Dar-es-Salaam, Tanzania , Genitourinary Medicine, 70:39-43.

Gray, R. and M. Wawer (1996). "Clinical / laboratory methods for the diagnosis of reproductive morbidity in population-based studies", Seminar on Innovative Approaches to the Assessment of Reproductive Health, IUSSP Committee on Reproductive Health and Population Institute, University of the Philippines, IUSSP, Liège, Belgium.

Grosskurth, H., F. Mosha, J. Todd et al. (1995). Impact of improved treatment of sexually transmitted diseases on HIV infection in rural Tanzania: randomised controlled trial , The Lancet, 346:530-536.

Heise, L. and C. Elias (1995). Transforming AIDS prevention to meet women s needs: A focus on developing countries , Social Science and Medicine, 40,7:931-943. 
Hunter, D., B. N. Maggwa, J. Mati et al. (1994). Sexual behavior, sexually transmitted diseases, male circumcision and risk of HIV infection among women in Nairobi, Kenya , AIDS, 8:93-99.

Kapiga, S., J. Shao, G. Lwihula and D. Hunter (1994). Risk factors for HIV among women in Dares-Salaam, Tanzania , Journal of Acquired Immune Deficiency Syndromes, 7:301-309.

Kapiga, S., B. Vuylsteke, M. Laga et al. (1997). Evaluation of STD diagnostic strategies among family planning clients in Dar es Salaam, Tanzania , Paper presented at the Annual Meeting of the Population Association of America, Washington D.C., March 27-29.

Kariba, J., B. Kariuki and B. N. Maggwa (1997). Integration of STI and HIV/AIDS with MCH-FP Services: A case study of the Nakuru Municipal Council s Project on Strengthening STD/AIDS Control, Nakuru Municipal Council and Africa OR/TA Project II, The Population Council, Nairobi, Kenya.

Kim, Y. M., C. Lettenmaier, D. Odallo et al. (1996). "Haki Yako: A Client-Provider Information, Education and Communication Project in Kenya", IEC Field Report Number 8, Johns Hopkins Center for Communication Programs, Baltimore, MD, USA.

Laga, M. (1992) Human Immunodeficiency Virus infection prevention: The need for complementary Sexually Transmitted Disease Control , pp131-144 in Germain, A., K. Holmes, P. Piot and J. Wasserheit (eds), Reproductive Tract Infections: Global Impact and Priorities for Women s Reproductive Health. Plenum Press, New York, NY, USA.

Langer, A. (1996). Impact assessment: what criteria do we use to demonstrate the importance of RTIs to policymakers? , pp39-45 in Grant, J. and D. Measham (eds) Reproductive Tract Infection. Lessons learned from the Field: Where do we go from here?, The Robert $\mathrm{H}$. Ebert Program on Critical issues in Reproductive Health and Population, The Population Council, New York, New York, USA.

Macro International (1997). Ethiopian Reproductive Health Survey: STD Pilot Study, Unpublished Report, Macro International, Calverton, Maryland, USA.

Maribe, L., B. N. Maggwa and I. Askew (1997). A Rapid Assessment Approach to Evaluating the Quality of Care in an Integrated Program: The Experience of Botswana, Ministry of Health, Botswana and the Africa OR/TA Project II, The Population Council, Nairobi, Kenya. (forthcoming)

Mason, K. (1994). HIV transmission and the balance of power between women and men: a global view , Health Transition Review, Supplement to vol. 4, 217-240.

Mayhew, S. (1996) Integrating MCH/FP and STD/HIV services: current debates and future directions , Health Policy and Planning, 11,4:339-353.

Mertens, T, M. Caräel, P. Sato et al. (1994). Prevention indicators for evaluating National AIDS Control Programs , AIDS, 8: 1359-1369.

Miller, R., K. Stein, K. Miller et al. (1996). "Measuring reproductive health care after Cairo: Findings from four Situation Analysis Studies in Africa", African Journal of Fertility, Sexuality, and Reproductive Health, 1,2: 92-100.

Miller, R., A. Fisher, K. Miller et al. (1997). The Situation Analysis Approach to Assessing Family Planning and Reproductive Health Services: A Handbook, Africa Operations Research and Technical Assistance Project, The Population Council, New York, New York, USA. 
Morris, M., C. Podhisita, M. Wawer and M. Handcock (1996). Bridge populations in the spread of HIV/AIDS in Thailand , AIDS, 10:1265-1271.

Moses, S., E. Muia, J. Badley et al. (1994). Sexual behaviour in Kenya: implications for sexually transmitted disease transmission and control , Social Science and Medicine, 39,12:1649-1656.

Mukaire, J., F. Kalikwari and B. N. Maggwa (1997). Integration of STI and HIV/AIDS Services with MCH-FP Services: A case study of the Busoga Diocese Family Life Education Program, Uganda, Busoga Diocese Family Life Education Program and Africa OR/TA Project II, The Population Council, Nairobi, Kenya.

Olukoya, A. and C. Elias (1996). Perceptions of reproductive tract morbidity among Nigerian women and men , Reproductive Health Matters, 7:56-65.

Piot, P. and J. Rowley (1992). Economic impact of Reproductive Tract Infections and Resources for their control , pp227-249 in Germain, A., K. Holmes, P. Piot and J. Wasserheit (eds), Reproductive Tract Infections: Global Impact and Priorities for Women s Reproductive Health. Plenum Press, New York, NY, USA.

Plummer, F., J. Simonsen, D. Cameron et al. (1991). Co-factors in male-female sexual transmission of Human Immunodeficiency Virus Type 1", Journal of Infectious Diseases, 163:233-239.

Schulz, K., J. Schulte and S. Berman (1992). Maternal health and child survival: Opportunities to protect both women and children from the adverse consequences of reproductive tract infections , pp145-184 in Germain, A., K. Holmes, P. Piot and J. Wasserheit (eds), Reproductive Tract Infections: Global Impact and Priorities for Women s Reproductive Health. Plenum Press, New York, NY, USA.

Temmerman, M., F. Ali, J. Ndinya-Achola et al. (1992). Rapid increase in both HIV-1 infection and syphilis among pregnant women in Nairobi, Kenya , AIDS, 6:1181-1185.

Twahir, A., B. N. Maggwa and I. Askew (1996). Integration of STI and HIV/AIDS Services with MCH-FP Services: A case study of the Mkomani Clinic Society in Mombasa, Kenya, Mkomani Clinic Society and Africa OR/TA Project II, The Population Council, Nairobi, Kenya.

Wasserheit, J. and K. Holmes (1992). Reproductive tract infections: Challenges for international health policy, programs and research , pp7-34 in Germain, A., K. Holmes, P. Piot and J. Wasserheit (eds), Reproductive Tract Infections: Global Impact and Priorities for Women s Reproductive Health. Plenum Press, New York, NY, USA.

WHO (1991). Management of patients with sexually transmitted diseases , World Health Organization Technical Report Series, 810. 